\title{
DESARROLLO DE LA APROPIACIÓN TECNOLÓGICA CON RECURSOS EDUCATIVOS ABIERTOS PARA EL APRENDIZAJE DE EDUCACIÓN BÁSICA PRIMARIA RURAL
}

\author{
Sandra Milena Lizarazo Gómez
}

Trabajo de grado para optar al título de:

Magister en Tecnología Educativa y Medios Innovadores para la Educación

Dr. Leonardo David Glasserman Morales Asesor tutor

Dra. María Soledad Ramírez Montoya Asesora titular

TECNOLÓGICO DE MONTERREY

Escuela de Graduados en Educación

Monterrey, Nuevo León. México

UNIVERSIDAD AUTÓNOMA DE BUCARAMANGA

Facultad de Educación

Bucaramanga, Santander. Colombia 


\section{Agradecimientos}

Agradezco a Dios primero que todo por haberme permitido iniciar y culminar otra nueva etapa de superación y logro personal y por ayudarme a no desfallecer.

A mi Madre por su gran apoyo incondicional, a mi Padre que aunque ya no está con vida, contribuyó al logro de mis sueños.

A mis hermanos, a mi esposo y a mis amigos (as) incondicionales que siempre estuvieron con una palabra de ánimo y que de una u otra forma aportaron un granito de arena para culminar esta meta.

A la Dra. María Soledad Ramírez Montoya, al Dr. Leonardo David Glasserman Morales, a mis compañeros de maestría entre ellos Donovan Daniel del Valle Jiménez, por contribuir con su experiencia, sus aportes significativos, su ayuda y motivación en cada instante para seguir adelante. 


\section{Desarrollo de la apropiación tecnológica con recursos educativos abiertos para el aprendizaje de educación básica primaria rural}

\section{Resumen}

El trabajo de investigación que aquí se presenta tuvo como objetivo analizar el desarrollo de la apropiación tecnológica en alumnos de tercer grado de educación básica de una primaria rural, con un ambiente de aprendizaje que integró recursos educativos abiertos de contenidos en el área de matemáticas de operaciones básicas (adición, sustracción, multiplicación y división), solución de problemas, lectura y escritura de números; con el fin de contribuir con la innovación en los ambientes de aprendizaje de educación básica en contextos rurales. La investigación se desarrolló en una escuela rural con estudiantes de tercer grado de educación básica primaria y se basó en un análisis cualitativo con un enfoque de estudio de casos, cuya pregunta de investigación fue: ¿Cómo se desarrolla la apropiación tecnológica en los alumnos de educación básica primaria rural al trabajar con recursos educativos abiertos? Este tipo de análisis permitió hacer observaciones, llevar registros de clase y examinar los casos particulares que se estaban presentando. Se tuvieron en cuenta tres categorías de estudio: nivel de apropiación tecnológica, evaluación de los entornos con REA e innovación con REA en ambientes educativos rurales. Los datos se analizaron a través de instrumentos como el registro de observación de las actividades significativas de los alumnos, el cuestionario, el diario del investigador y los trabajos de los alumnos resultado de la integración de REA. Los resultados indican que: a) La familiarización de la apropiación tecnológica se desarrolla cuando los alumnos conocen por primera vez los recursos tecnológicos, b) la utilización de la apropiación tecnológica se presenta cuando los alumnos utilizan dispositivos y recursos tecnológicos en actividades cotidianas de clase, c) la integración de la apropiación tecnológica se presenta cuando los alumnos se apoyan en los recursos tecnológicos para realizar otras actividades diferentes a las de clase, d) la reorientación de la apropiación tecnológica se desarrolla cuando los alumnos entienden que los dispositivos y recursos tecnológicos son herramientas para la construcción de conocimiento y e) la evolución de la apropiación tecnológica se desarrolla cuando los alumnos comprenden que los recursos tecnológicos tienen diferentes usos y aplicaciones. 


\section{Índice}

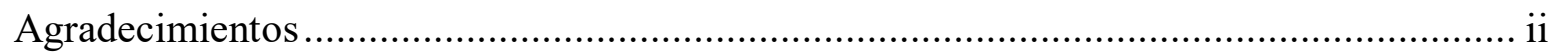

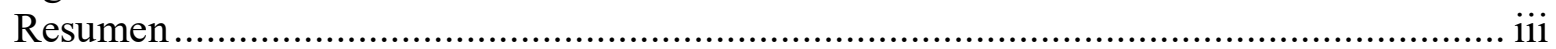

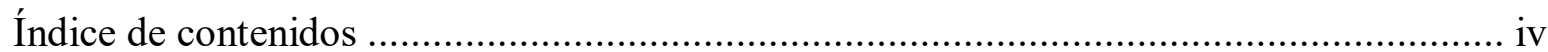

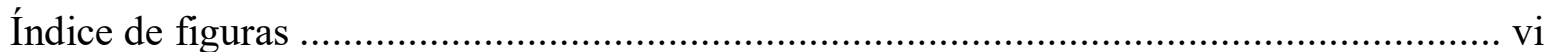

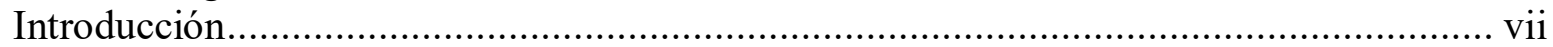

Capítulo 1. Naturaleza y dimensión del tema de investigación ..................................1

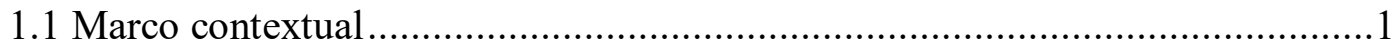

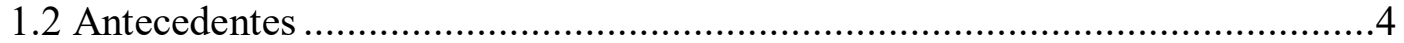

1.3 Planteamiento del problema .................................................................6

1.4 Objetivo ......................................................................................... 7

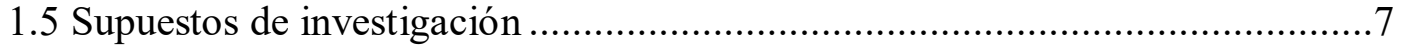

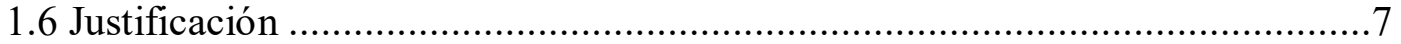

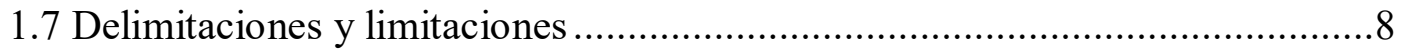

1.8 Definición de términos .................................................................

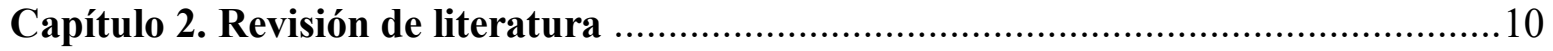

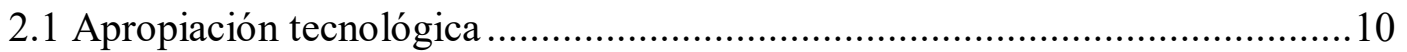

2.1.1 Conceptualizaciones y desarrollo de apropiación tecnológica ................10

2.1.2 Tipos de apropiación tecnológica y cómo se enseñan .........................12

2.1.3 Evaluación de apropiación tecnológica ............................................14

2.2 Recursos Educativos Abiertos para la enseñanza de la educación básica

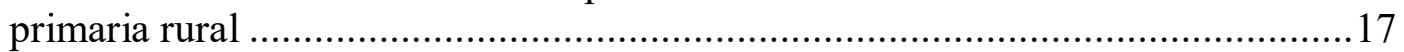

2.2.1 Conceptualizaciones y desarrollo de Recursos Educativos Abiertos.......17

2.2.2 Tipos de Recursos Educativos Abiertos y cómo se enseñan ..................20

2.2.3 Innovación con Recursos Educativos Abiertos ..................................22

2.3 Investigaciones relacionadas con apropiación tecnológica y Recursos

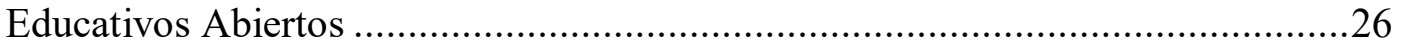

2.3.1 Investigaciones relacionadas con apropiación tecnológica ...................26

2.3.2 Investigaciones relacionadas con algún otro elemento de los Recursos

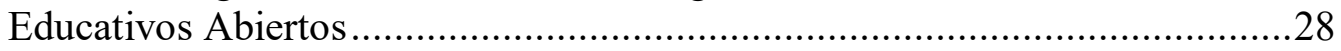

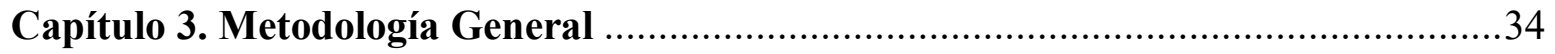

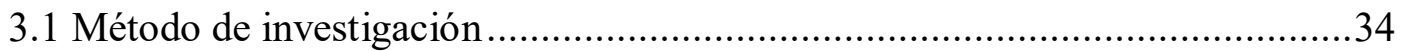

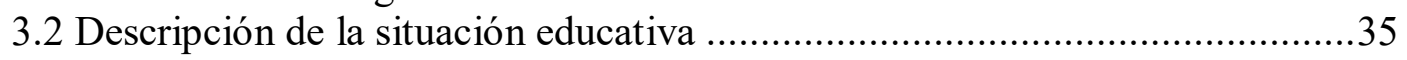

3.3 Población y muestra ...................................................................... 41 
3.4 Tema, categorías e indicadores de estudio..........................................42

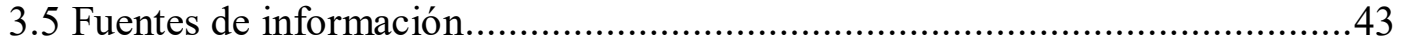

3.6 Técnicas de recolección de datos ..........................................................44

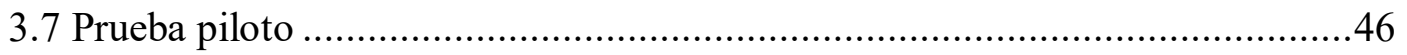

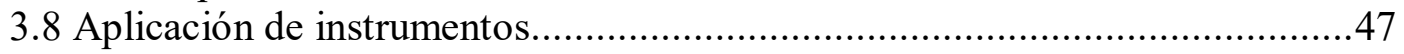

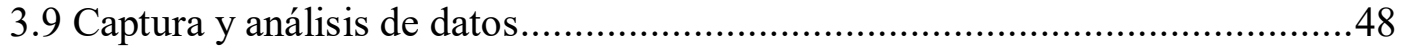

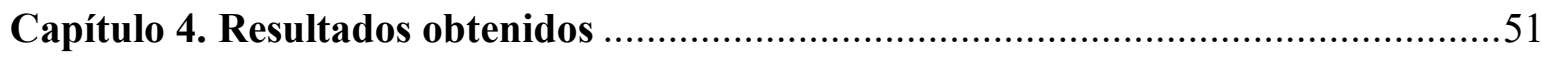

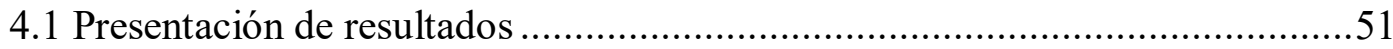

4.2 Análisis e interpretación de resultados ................................................62

Capítulo 5. Discusión, conclusiones y recomendaciones ......................................70

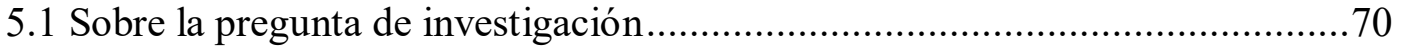

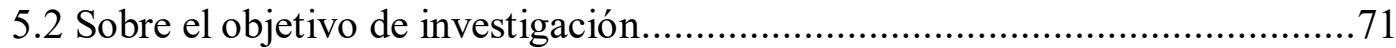

5.3 Sobre los supuestos de investigación .................................................... 72

5.4 Recomendaciones para futuras investigaciones ..................................... 73

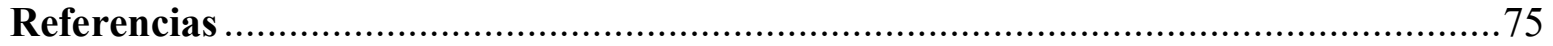

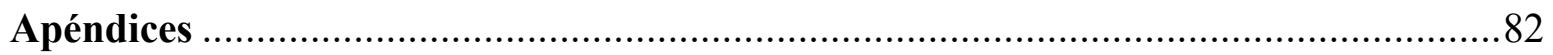

Apéndice A. Cuadro de triple entrada ....................................................... 82

Apéndice B. Registro de Observación de las actividades significativas de los

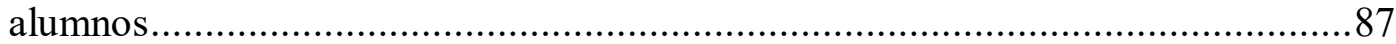

Apéndice C. Diario del investigador ......................................................... 88

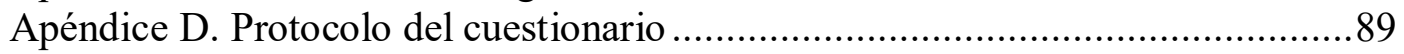

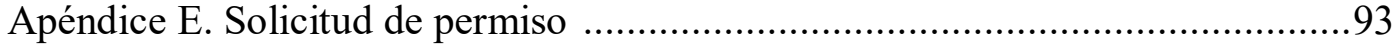

Apéndice F. Autorización para realizar el proyecto........................................94

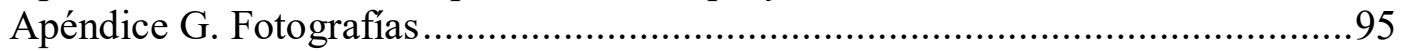

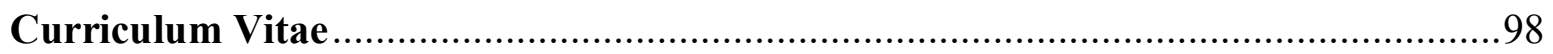




\section{Índice de figuras}

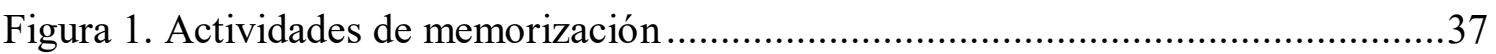

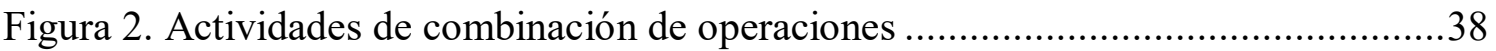

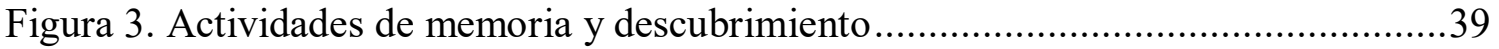

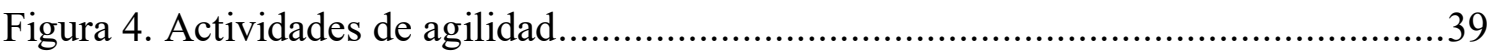

Figura 5. Actividades de múltiplos de un número .............................................. 40

Figura 6. Distribución de los estudiantes en el aula de clases ...................................52

Figura 7. Estudiante resolviendo actividades con REA .....................................54

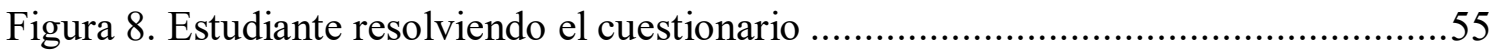

Figura 9. Estudiantes atentos a las explicaciones de la docente ...............................56

Figura 10. Actividad relacionada con los múltiplos de un número...........................57

Figura 11. Estudiante resolviendo el cuestionario ................................................59

Figura 12. Estudiantes realizando multiplicaciones ............................................60

Figura 13. Estudiante resolviendo el cuestionario ...............................................62

Figura 14. Fotografías del aula de clases.......................................................... 95

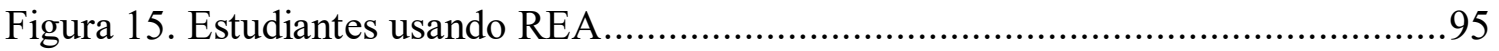

Figura 16. Estudiantes realizando actividades con REA ....................................96

Figura 17. Estudiantes realizando actividades con REA .......................................96

Figura 18. Actividad de operaciones matemáticas básicas......................................97 


\section{Introducción}

Alrededor del mundo, las tecnologías de información y comunicación (TIC) están revolucionando las actividades cotidianas de los seres humanos, el trabajo, la educación, el hogar, la diversión, la comunicación, el deporte, entre muchas otras. Pero que importante detenerse a pensar en los beneficios que pueden traer al ámbito educativo, si esa innovación tecnológica se usa y aprovecha correctamente.

Esta investigación se basó en un análisis cualitativo con un enfoque de estudio de casos, a través de categorías de estudio como el nivel de apropiación tecnológica, evaluación de los entornos con REA e innovación con REA en ambientes educativos rurales que permitieron analizar los resultados y presentar los hallazgos de la misma.

El trabajo está estructurado en cinco capítulos, el primero hace mención a la Naturaleza y dimensión del tema de investigación, el cual lleva a una mirada específica de cada uno de los apartados centrados en la importancia de la incorporación de herramientas tecnológicas en el ámbito educativo en contextos rurales como lo son el marco contextual, los antecedentes, el planteamiento del problema, el objetivo de la investigación, así como los supuestos que surgieron con el paso de la misma, la justificación, delimitación,

limitaciones y la definición de algunos términos relacionados con el presente estudio también hacen parte de este capítulo.

En el capitulo 2 se hace una revisión de literatura de la apropiación tecnológica y los REA, su conceptualización, desarrollo, tipos, evaluación y cómo se enseñan, así como la 
innovación con REA y las investigaciones relacionadas, en los que se pretende orientar hacia la incorporación tecnológica en contextos rurales.

El capítulo 3 aborda la metodología general realizada dentro de ésta investigación, cuyo objetivo fue analizar el desarrollo de la apropiación tecnológica en alumnos de tercer grado de educación básica de una primaria rural, con un ambiente de aprendizaje que integró recursos educativos abiertos de contenidos en el área de matemáticas de operaciones básicas (adición, sustracción, multiplicación y división), solución de problemas, lectura y escritura de números; con el fin de contribuir con la innovación en los ambientes de aprendizaje de educación básica en contextos rurales. Este capitulo deja ver, el método de investigación, la población y muestra, temas, categorías e indicadores de estudio, fuentes de información, técnicas de recolección de datos, prueba piloto, aplicación de instrumentos y captura y análisis de datos.

El capítulo 4, presenta los resultados obtenidos a través de las técnicas de recolección como las observaciones, el cuestionario, el diario del investigador, así como de los trabajos de los estudiantes y el análisis cualitativo del estudio de casos por las categorías establecidas dentro de la investigación. En ellos, se relatan los hallazgos obtenidos en cada una de las fases de la apropiación tecnológica.

Finalmente, en el capítulo 5 se da respuesta a la pregunta de investigación, el alcance de los objetivos y los supuestos de investigación así como recomendaciones para futuras investigaciones. 


\section{Capítulo 1. Naturaleza y Dimensión del Tema de Investigación}

El siguiente capítulo abarca aspectos importantes que permiten conocer el escenario de aplicación del proyecto de investigación, el cual lleva a una mirada específica de cada uno de los apartados centrados en la importancia de la incorporación de herramientas tecnológicas en el ámbito educativo en contextos rurales. Dentro de este capítulo se aborda el marco contextual, los antecedentes, el planteamiento del problema, el objetivo de la investigación, así como los supuestos que surgieron con el paso de la misma. La justificación, delimitaciones, limitaciones y la definición de algunos términos relacionados con el presente estudio también hacen parte de este capítulo.

\subsection{Marco Contextual}

El camino hacia la innovación con tecnología en contextos educativos se ha ido abriendo paso con el transcurso del tiempo. El desarrollo de competencias a través del uso de herramientas tecnológicas, se ha encaminado desde centros internacionales como el Instituto para la Utilización de las tecnologías de la Información en la Educación (ITIE) de la Organización de las Naciones Unidas para la Educación, la Ciencia y la Cultura (UNESCO), cuyo objetivo es contribuir al diseño y a la implementación de las tecnologías en la educación para reducir la brecha digital y construir conocimiento (UNESCO, 1997). Según Midoro (2013) el desarrollo de competencias en los estudiantes tiene tres etapas, la tecnología de la alfabetización, profundización del conocimiento y la creación del conocimiento, las cuales dependen de la capacidad del docente para incorporar las nuevas tecnologías al aula de clases. De ahí la importancia que el docente desarrolle destrezas y 
habilidades para llevar a cabo una óptima apropiación de las Tecnologías de Información y Comunicación (TIC).

Incluso, para entrar en un análisis más profundo acerca de la incorporación de las herramientas tecnológicas en el ámbito educativo, es pertinente indicar algunas estadísticas que han posicionado a Colombia en un escalafón alto en cuanto a TIC y son las que menciona la Comisión de Regulación de Comunicaciones (CRC). De acuerdo con Hernández y Villarreal (2013) en un estudio realizado entre de diciembre de 2012 y septiembre de 2013, se logró aumentar de 61\% a 70\% de alumnos con acceso a internet en la escuela y el porcentaje de docentes capacitados en TIC pasó de 16,9\% a 22,17 \%. Este hecho permite evidenciar que se está trabajando fuerte desde los entes gubernamentales para implementar en la educación herramientas tecnológicas innovadoras.

Pero no sólo la CRC, menciona la existencia de proyectos y avances con TIC, para mejorar la educación en Colombia. Existe un proyecto nacional de uso y apropiación de medios y TIC en el proceso educativo, cuyo objetivo es "promover el uso y apropiación de las TIC al servicio de mejoramiento de la calidad y equidad de la educación y la competitividad de las personas y del país" (Zea, 2007, p. 4), dentro del cual se evidencia el interés por incorporar recursos tecnológicos en los centros educativos para crear escenarios de innovación y experiencia de los integrantes de la comunidad educativa. Asimismo, el programa del gobierno nacional de Colombia, llamado Computadores para Educar (CPE), promueve las TIC como un factor de desarrollo equitativo y sostenible en Colombia para cerrar la brecha digital mediante la donación de equipos de cómputo a las instituciones educativas públicas del país y lograr una educación de calidad que responda a las 
expectativas y demandas de la sociedad actual y permitir que tanto docentes como estudiantes interactúen con las herramientas y lleven a cabo con ellas procesos de construcción y significación del conocimiento (CPE, 2008).

A propósito de ello, las entidades departamentales no se quedan atrás en cuanto al uso e incorporación de TIC en las aulas de clases, el departamento de Santander en Colombia creó un Plan Estratégico Departamental de Ciencia, Tecnología e Innovación (PEDCTI Santander) cuya planeación se proyecta hasta el año 2020 y que considera la dimensión territorial de las provincias con el fin de convertir a Santander en referencia para el resto del país en cuanto a Ciencia, Tecnología e Innovación (Arenas, 2013). De igual manera con ayuda de CPE se ha ido dotando a algunas instituciones con equipos de cómputo, tableros digitales y otras herramientas tecnológicas que brindan espacios de innovación educativa dentro de las aulas de clases (SeTIC, 2012). En otras palabras, Santander se quiere consolidar como el principal artífice del uso de las herramientas tecnológicas, no solo en el ámbito educativo, sino empresarial y social.

Por lo tanto, resulta interesante pensar que se está contribuyendo en la reducción de la brecha digital y que en su mayoría, las instituciones educativas han logrado incorporar las herramientas tecnológicas dentro de sus actividades escolares, pero la realidad es otra, si se hace referencia a la institución en la cual se desarrolló está investigación. El estudio se llevó a cabo en una institución educativa rural pública, con infraestructura poco adecuada, con una sola aula de proporciones reducidas, cuya capacidad permitía atender a 19 estudiantes de los grados preescolar y primaria pertenecientes a un nivel socioeconómico bajo. 
La institución no contaba con equipos de cómputo, ni con alguna otra herramienta tecnológica, excepto un televisor y un reproductor de video (DVD) que no funcionaba correctamente. Contaba con poca iluminación e incluso los recursos de consulta y apoyo académico (libros, guías, folletos, entre otros) estaban desactualizados, por la cual era complicado el desarrollo de actividades innovadoras con los estudiantes.

\subsection{Antecedentes}

Antes de hacer mención de algunos estudios relacionados con esta investigación es pertinente señalar la importancia de los REA dentro del contexto educativo, debido a que son herramientas innovadoras que contribuyen a que el estudiante tenga un acercamiento y apropiación tecnológica significativa para lograr la construcción de su aprendizaje. Luego que la UNESCO en el año 2002 hubiese acuñado el término de los recursos educativos abiertos (REA), la Organización para la Cooperación y el Desarrollo Económico (OCDE, 2008) menciona que las iniciativas del movimiento de los REA se dieron en países como Estados Unidos, China, Japón y Francia a partir del año 2006. Las acciones emprendidas por diferentes naciones denotaban los intereses por la incorporación tecnológica en la educación y comenzaba a tomar fuerza un movimiento de conocimiento abierto que invitaba a que otras naciones se fueran sumando poco a poco.

Aparecieron en escena otros países como India, ya que de acuerdo con la Secretaría de Estado de Educación, Formación Profesional y Universidades (2012) en aquel país se le dio un enfoque nacional al uso de los REA y en el 2007 se lanzó la Iniciativa E-content seguida de varias actividades y proyectos relacionados con REA. En tanto en el 2009, el Ministerio Holandés de Educación lanzó un programa nacional con el objetivo de 
incorporar los REA en todos los sectores educativos; éste se desplegó desde el año 2009 hasta al año 2013. Por último, los Departamentos de Trabajo y Educación de los Estados Unidos anunciaron en 2011 un programa de cuatro años con el objetivo de crear REA para las universidades públicas y para la formación profesional. De igual manera otros países como Reino Unido, Australia, Rusia, Brasil, Cuba, España, entre otros están desarrollando iniciativas afines a proyectos donde se incluya el uso pedagógico de los REA. De ahí la importancia de aplicar REA, incluso en contextos educativos rurales, para aprovechar todo aquello que éstos permiten lograr aspectos educativos.

Es evidente que a nivel mundial se han realizados diferentes proyectos de investigación encaminados hacia el uso de REA en el contexto educativo, en aras de desarrollar procesos de apropiación tecnológica e innovación. Martínez, Mendías y Mendoza (2010) son algunos de los que realizaron una investigación acerca de la forma en que se usa la tecnología y se adoptan REA en las escuelas primarias, para llevar a cabo procesos innovadores. Los investigadores realizaron un estudio de tres casos en diferentes regiones de México, en donde los tres profesores implementaron REA en los procesos lectores, obteniendo como resultado que estos son de utilidad en la práctica educativa, sin desconocer que existen limitaciones para su uso como la falta de capacitación docente y/o el desconocimiento de la existencia de los REA. En otras palabras, cualquier contexto en los que se usen herramientas tecnológicas van a presentar limitantes y áreas de oportunidad para lograr mejores resultados.

En la misma investigación se evidencia claramente que la aplicación de recursos tecnológicos puede encontrarse de frente con limitaciones, entre ellas la conectividad, la 
infraestructura, la capacitación docente, entre otras. Pero es de resaltar que una vez superadas estas limitaciones los REA seleccionados de acuerdo con los objetivos que se pretenden alcanzar, serán muy útiles. Por otra parte, Rivera, López, y Ramírez (2011) buscaban con su investigación qué estrategias de comunicación se podían usar para potenciar el uso de REA en un ambiente de enseñanza innovador, lo cual es importante a la hora de analizar cómo los docentes usan los REA en las actividades escolares.

La muestra fue tomada de una institución privada con estudiantes de estrato medio alto de los cuales la mayoría contaban con computadores en las casa. Algunos resultados se orientaron hacia la diferencia que encontraron los docentes entre los REA y lo que ofrece libremente internet, así como a respetar los derechos de autor, y a que se debe realizar un plan estratégico para el uso del REA, entre otros. El análisis de estas investigaciones es importante debido a que sirven como punto de comparación con la institución estudiada, por tratarse de un contexto totalmente diferente y que va a permitir relacionar o diferenciar elementos cruciales dentro del estudio.

\subsection{Planteamiento del Problema}

Al encontrar contextos con limitaciones y en los cuales se necesita buscar estrategias innovadoras para el desarrollo de procesos de enseñanza aprendizaje, se hace pertinente realizar estudios relacionados con innovación tecnológica debido a que permite tanto al maestro como al estudiante interactuar con nuevas herramientas de aprendizaje pensadas para facilitar la construcción del conocimiento de una manera más dinámica y atractiva. De igual manera es importante que el docente tenga la capacidad y disposición de enfrentarse a estos nuevos retos y permitir que sus estudiantes también así lo hagan. No hay que olvidar 
que aún hay contextos en los cuales la interacción de los estudiantes con la tecnología es poca o nula por lo cual, se determinó la siguiente pregunta de investigación ¿Cómo se desarrolla la apropiación tecnológica en los alumnos de educación básica primaria rural al trabajar con recursos educativos abiertos?

\subsection{Objetivo}

El objetivo del estudio fue analizar el desarrollo de la apropiación tecnológica en alumnos de tercer grado de educación básica de una primaria rural, con un ambiente de aprendizaje que integró recursos educativos abiertos de contenidos en el área de matemáticas de operaciones básicas (adición, sustracción, multiplicación y división), solución de problemas, lectura y escritura de números; con el fin de contribuir con la innovación en los ambientes de aprendizaje de educación básica en contextos rurales.

\subsection{Supuestos de Investigación}

Es pertinente plantear que si los estudiantes de básica primaria de un contexto rural no han tenido un acercamiento e interacción con la tecnología y cuando esto ocurra, querrán regresar a métodos de aprendizaje tradicionales.

La aplicación de REA con características atractivas, motivadoras y afines con el nivel de enseñanza de los estudiantes, logra en ellos mayor interés y desempeño académico en cada una de las áreas en las que se emplean.

\subsection{Justificación}

En un contexto donde predomina cada vez más el uso de la tecnología a través del empleo de herramientas innovadoras como los objetos de aprendizaje, los REA, podcasts, videos educativos entre otras se pretende que los procesos de enseñanza aprendizaje sean 
flexibles, innovadores, reutilizables y adaptables, que busquen generar la calidad educativa, tanto en entornos urbanos como en entornos rurales. El brindar la oportunidad a estudiantes que se desenvuelven en entornos socioculturales rurales, que interactúen y se apropien de nuevas tecnologías, por ejemplo a partir de REA, permite abrir paso a ambientes equitativos en donde la igualdad y el derecho a la calidad vayan cerrando la brecha digital que aún se vive en el país.

Los REA contribuyen a reducir esta brecha digital, debido a sus características, además permiten al docente utilizar y reutilizar el material en diferentes contextos y situaciones de aprendizaje, lo cual es valioso a la hora de trabajar interdisciplinariamente y sobre todo al momento de involucrar al estudiante con nuevas formas de interacción y de construcción de significado.

La aplicación de REA ha demostrado que posee variedad de alternativas prácticas e innovadoras que contribuyen eficientemente a la construcción de conocimiento por parte de los estudiantes. Es por ello que a partir de esta investigación se hizo especial énfasis en conocer cómo se desarrolla la apropiación tecnológica de REA con estudiantes de la básica primaria rural debido a que este contexto ha sido poco estudiado.

\subsection{Delimitaciones}

El proyecto de investigación se llevó a cabo con estudiantes de $2^{\circ}, 3^{\circ}, 4^{\circ}$ y $5^{\circ} \mathrm{de}$ educación primaria en una institución pública, rural del departamento de Santander, en Colombia, durante los meses de abril a agosto del 2014 a través de una metodología de estudio de casos. 
El contexto estudiado presentó limitaciones como las siguientes: no contaba con equipos de cómputo por lo tanto no tenía una sala de sistemas, la escuela tenía grupos multigrados por lo que los niveles de aprendizaje de los participantes eran diferentes y el tiempo de clase dedicado a cada grupo era escaso. Además de que se presentan situaciones del contexto existieron otros factores externos como el clima, que impidió o dificultó el transporte de los estudiantes, la infraestructura pública al no contar con energía eléctrica en los hogares, por mencionar algunos. El contexto claramente reflejó una amplia brecha digital en contraste con otras instituciones ubicadas en entornos urbanos.

\subsection{Definición de términos}

- Apropiación tecnológica: Hacer propia una herramienta tecnológica para adaptarla y usarla dentro del contexto de interacción (Overdijk y Diggelen, 2006).

- Recursos Educativos Abiertos: Materiales tecnológicos de enseñanza, de libre circulación y distribución creados para ser utilizados y adaptados dentro de la práctica educativa como recurso innovador (UNESCO, 2002).

- Innovación educativa: Incorporar nuevas formas de enseñanza aprendizaje, buscando la experimentación e interacción con el contexto (Cobo, 2007).

- Brecha digital: Desigualdad de oportunidades que tienen personas o instituciones de ciertos contextos para acceder a la tecnología (Cabero, 2004).

- Práctica educativa: Proceso de interacción entre maestros y alumnos en el cual se llevan a cabo actividades de enseñanza aprendizaje (Malpica, 2013). 


\section{Capítulo 2. Revisión de literatura}

Éste capítulo aborda la conceptualización, desarrollo, tipos y evaluación de la apropiación tecnológica y los Recursos Educativos Abiertos (REA), así como las investigaciones relacionadas con estos temas. Se busca centrar la atención en cómo se desarrolla dicha apropiación en estudiantes rurales, en donde no se cuenta con herramientas tecnológicas que orienten los procesos de enseñanza y aprendizaje hacia la innovación. Por ello, es importante que los estudiantes tengan un acercamiento e interacción con la tecnología para aplicarlas en la construcción de conocimiento, a través del uso de Recursos educativos abiertos (REA).

\subsection{Apropiación tecnológica}

\subsubsection{Conceptualizaciones y desarrollo de apropiación tecnológica. El momento}

de abrir paso a nuevas herramientas innovadoras dentro de los procesos de enseñanza aprendizaje llegó hace un tiempo, con la convicción de mejorar la práctica educativa de docentes y estudiantes. Por ello, es necesario ahondar en el desarrollo de la apropiación tecnológica en la educación primaria rural, y tener claridad en esta definición para lograr mejores resultados. Autores como Colás y Jiménez (2008) y Overdijk y Diggelen (2006) expresan que la apropiación es aquella forma en la cual el sujeto toma las herramientas tecnológicas y las hace suyas para así poderlas utilizar en el contexto en el cual se desenvuelve. Lo que conlleva no solo a cambios en los conocimientos sino en las propiedades de la tecnología. Es decir, la apropiación permite que haya una exploración de la herramienta tecnológica, que permite una eficacia en los procesos educativos que se pretenden realizar. 
Además que la apropiación tecnológica se tome de forma significativa para mejorar en aspectos como procesos de aprendizaje y de enseñanza, ha de contribuir al desarrollo de habilidades. Por ello, Echeverría (2008) hace especial énfasis a la incorporación de las herramientas tecnológicas en las acciones humanas, lo que significa que a partir de la interacción del sujeto con la herramienta, se van a incrementar sus capacidades y habilidades para apropiarse de la misma y desarrollar adecuados procesos de aprendizaje. Por lo tanto, la apropiación e incorporación de las herramientas tecnológicas en las personas o instituciones, no puede ser solo para desarrollarlas sino incrementarlas y profundizarlas, lo que hace más relevante su uso. Cuando se busca incorporar una nueva herramienta tecnológica innovadora dentro de un contexto educativo, es pertinente que el usuario adapte el instrumento tecnológico en una actividad dirigida al objetivo (Overdijk y Diggelen, 2006). Es más, una de las habilidades que se considera importante es la capacidad de explorar y entender la finalidad del instrumento para luego emplearlo en una actividad donde no solo es importante saber cómo aplicar un contenido con el apoyo de tecnología, sino que se debe lograr un proceso de construcción y sentido de la acción que se está realizando.

Incluso, hay características que se deben tener presentes dentro del aprendizaje con tecnología, para así encaminarse a desarrollar un verdadero proceso de evolución educativa. De acuerdo con Montes y Ochoa (2006) las características desde el enfoque de aprender de la tecnología son: organización, almacenamiento y formalismo mientras que las del enfoque aprender con la tecnología son la interactividad, dinamismo, multimedia e hipermedia, de las cuales estas últimas se convierten en un camino a seguir en esta investigación. Mejor 
dicho, los dos puntos de vista claves dentro del uso de la tecnología, están guiados hacia las formas en que ellas se apropien, ya sea de aprender con o aprender de la tecnología, desde el diseño de ambientes de aprendizaje en los cuales el estudiante interactúe con su propio conocimiento y se haga más atractiva su manera de aprender, siempre y cuando los objetivos propuestos se puedan alcanzar y haya claridad en ellos.

Recapitulando, no solamente es pertinente ver la tecnología como un camino directo hacia la construcción del conocimiento, sino como un escalón que permite irlo alcanzando. Para Laffey (2004), el proceso de aprender a usar la tecnología no implica que sea únicamente el docente quien use la herramienta o diseñe actividades, sino que los estudiantes desarrollen las capacidades para también hacerlo. De ahí, que esto no implica que sea fácil, pero tampoco imposible, todo depende del interés, accesibilidad, objetivos claros de uso, entre otros aspectos claves para dar pie a la apropiación tecnológica.

2.1.2 Tipos de apropiación tecnológica. Así las cosas, la apropiación tecnológica se puede realizar a partir de tipologías que tracen el sendero por el cual se logre efectivamente la misma. Son Hooper y Rieber (1995) quienes proponen cinco fases que permiten entender la apropiación tradicional y contemporánea de la tecnología en la educación. Tales fases son: familiarización, utilización, integración, reorientación y evolución. Los autores son claros al expresar que los profesores deben progresar a través de estas cinco fases para evitar que la tecnología sea aplicada erróneamente o no funcione como debe ser.

Es más, la calidad y éxito de una verdadera apropiación se debe dar a través de espacios concretos de interacción en los cuales se aproveche al máximo la herramienta, por eso estas fases llevan un orden lógico de uso (Hooper y Rieber, 1995). La familiarización 
permite una aproximación a la tecnología, un conocimiento de la misma. La segunda fase es la aplicación de la tecnología en el aula, la integración tiene que ver con designar responsabilidades a la tecnología, la reorientación a replantear los objetivos propuestos para el trabajo en el aula y la evolución es la fase en la que el profesor debe tener claro que no existe una sola herramienta de trabajo y que su práctica educativa debe estar en constante cambio. De ahí que es claro llevar procesos de avance en donde cada etapa de paso a la otra y se logre el objetivo propuesto.

A propósito de esto, toda herramienta que se utilice dentro del aula de clase, ha de ser evaluada. De acuerdo con Zermeño, Rocha, Aguirre, Muñoz y Rocha (2007) la apropiación de las TIC implica no solo contar con los recursos, sino tener acceso a contextos en donde se interactúe y se promueva la práctica en ámbitos reales no simulados, lo que conlleva a usar las TIC de forma significativa para el sujeto. La enseñanza de la tecnología en ambientes educativos se torna significativa siempre y cuando el estudiante interactúe con la herramienta dentro de su contexto de aprendizaje.

El llevar a la práctica cualquier tipo de enseñanza permite apropiarse fácilmente de ella, pero si se centra la mirada a contextos rurales donde la tecnología es escasa o simplemente aún existe una brecha digital, ¿cómo se daría tal apropiación? Es Toboso (2013) quien aporta ideas al respecto, mencionando que se debe incluir tanto la práctica de uso como la de no uso, es decir, que así pareciera que al hacer referencia a esta última no esté presente la tecnología, estaría de una forma discursiva pero no experimental. En otros términos, habría una apropiación teórica, la cual sería útil cuando se dé la implementación tecnológica. 
2.1.3 Evaluación de apropiación tecnológica. Ante cualquier tipo de apropiación tecnológica y como toda herramienta innovadora, debe existir un sistema de evaluación que permita valorar la eficacia del recurso que se empleó. Por su parte, Colás, Jiménez y Rodríguez (2005) mencionan una propuesta de indicadores para la evaluación de los aprendizajes con TIC, los cuales se basan en el dominio, la privilegiación, la reintegración y apropiación de la herramienta tecnológica, y que permiten determinar la eficacia de ésta. Por lo tanto, cuando existe dominio del aprendizaje, de herramientas o de habilidades, es más fácil que exista una apropiación, dado a que por el hecho de contar con los medios y recursos no implica que haya una significación, es decir, que se presente un aprendizaje significativo guiado por el planteamiento de objetivos claros a la hora de llevar a cabo una actividad educativa.

En cualquier caso cuando una institución educativa diseñe un curriculum flexible el cual permita la incorporación y apropiación de las TIC, logrará llevar a cabo procesos significativos de aprendizaje tecnológico. Es más, cada proceso educativo conlleva hoy en día un portafolio de herramientas tecnológicas innovadoras que abren paso al cambio y a espacios de calidad educativa. Por ello, Sinisterra (2008) menciona herramientas como los foros, el chat, el e-mail, las presentaciones con componentes de animación e interactividad, el software de diseño, la videoconferencia, el trabajo por tareas entre otros, que representan la base para que la comunicación con el estudiante sea armónica. Es así como, son variados los medios con los cuales se puede evaluar la apropiación tecnológica, debido a que ella misma brinda las herramientas. 
A propósito de instrumentos de evaluación pertinentes para la apropiación tecnológica y que sean claros a la hora de valorar las herramientas empleadas, Barrett (2003) menciona las encuestas de los participantes o las entrevistas y la observación realizada por el evaluador como unos de estos instrumentos en la cual se permita verificar la eficacia y eficiencia de la herramienta y sus alcances dentro de los procesos educativos.

Lo más indicado es que los principales participantes en los procesos evaluativos sean quienes han usado o implementado la estrategia tecnológica porque son los que han estado en interacción con ella. Por tanto, Montes y Ochoa (2006), al hablar sobre la evaluación de la apropiación tecnológica, mencionan como primera medida enfocarse en comparar los resultados académicos entre los estudiantes que se apoyaron en TIC y los que los hicieron a través de métodos tradicionales, así como las actitudes que éstos tomaron frente al uso de tecnología y por último la satisfacción alcanzada por ellos al incluir dentro de su proceso de aprendizaje herramientas tecnológicas. Es decir, a través del acceso y uso del recurso es que parte el proceso evaluativo, no se podría evaluar si no se ha interactuado con la herramienta.

En conclusión, la apropiación tecnológica en las instituciones educativas se da a partir del acceso que tanto docentes como estudiantes tengan con la herramienta, la cual se puede convertir en un gran aliado para la construcción de conocimiento, en donde sea el participante quien establezca sus propios niveles de aprendizaje dependiendo de la facilidad con que se desenvuelva en el uso de la herramienta. Es más, si el proceso de apropiación tuviera alguna relación con la edad de la persona que la use, se pensaría que sólo los docentes jóvenes serían capaces de incorporar TIC dentro del aula de clases (Cobo y 
Moravec, 2011), lo cual estaría marginando las capacidades de personas de mayor o menor edad, apartándolos de cierta forma hacia las prácticas innovadoras de la educación, sin pensar si lo hacen es por falta de alfabetización digital.

Por lo tanto, es necesaria una alfabetización digital, debido a que existen docentes y estudiantes cuyos contextos y escasos recursos, no les han permitido el uso, interacción y apropiación de herramientas tecnológicas que contribuyan a un acceso real a la tecnología. El acceso a la tecnología debe significar algo más que computadoras y conexiones (Bridges, 2004). Es más, se podría decir que así se cuenta con las herramientas, éstas no cumplirían su verdadera función si no se utilizan efectivamente. Incluso, en hogares, instituciones o comunidades rurales dónde ni siquiera se cuenta con televisión, telefonía, equipos de computo o cualquier otro tipo de recurso tecnológico se abren interrogantes acerca de cómo estas personas podrían apropiarse más fácilmente a un medio innovador, si nunca han interactuado con él.

Pues bien, sería oportuno mencionar que dicha apropiación tendría mayor significado debido a que se evitaría caer en las malas prácticas que se le da a la tecnología, por ejemplo, en contextos como el urbano en donde la tecnología se resume en la mayoría de casos al mero entretenimiento y ocio o a su uso simplemente porque está de moda o porque facilita las actividades del profesor, sin encaminarse a lo propio de la educación basada en TIC. Es preciso pensar que existen espacios, tiempos, oportunidades y posibilidades gratuitas para que el profesor se informe, forme, actualice y se provea de recursos para innovar en el aula, pues resulta totalmente injustificado que se siga con las mismas concepciones sobre la función de los profesores y alumnos dentro la práctica educativa 
(Abelleira, 2011). Es decir, se debe abrir un espacio personal para pensar si verdaderamente se está cumpliendo el objetivo al usar alguna herramienta dentro del aula.

En ese sentido, el docente debe asumir un rol en el cuál las limitaciones o brechas que estén presentes en la institución, pasen a un segundo plano y se convierta en el actor responsable de gestionar y abrir paso a cambios que mejoren significativamente su actividad educativa. Para Sunkel, Trucco y Möller (2011), la incorporación de las TIC en la educación y la formación de criterios y competencias de los estudiantes, depende del rol de intermediación del docente. Es así, que el tiempo de culpar únicamente a los entes o sistemas gubernamentales, se deja de lado y se pasa a trabajar arduamente en la gestión por adquirir recursos o mejorar las condiciones de los procesos de enseñanza aprendizaje.

\subsection{Recursos Educativos Abiertos para la enseñanza de la educación básica primaria rural}

Conforme la ciencia avanza y el mundo se enfrenta a nuevos cambios, como la educación de calidad, se evidencia que aún no existe una cobertura total en zonas rurales y urbanas. Como apunta Belleï (2013) es importante llevar a cabo una formación de competencias digitales dentro del contexto educativo para entrar a la sociedad del conocimiento. En efecto, el uso de las herramientas tecnológicas es primordial, no solo para la alfabetización digital, sino para el desarrollo de competencias.

\subsubsection{Conceptualizaciones y desarrollo de Recursos Educativos Abiertos.}

Los Recursos Educativos Abiertos (REA) son una oportunidad para que los docentes empleen en sus aulas herramientas innovadoras, sin incurrir en altos costos o dificultad en el acceso, pues son materiales gratuitos y que utilizados apropiadamente optimizan el 
trabajo en el aula de clases y la construcción de conocimientos en los estudiantes, así como la interacción de ellos con dichas herramientas. Por lo tanto la UNESCO (2002) define los recursos educativos de libre acceso como materiales de enseñanza, aprendizaje o investigación que se encuentran en el dominio público o que han sido publicados con una licencia de propiedad intelectual que permite su utilización, adaptación y distribución gratuitas. Así las cosas, se hace importante su aplicación en contextos con poco acceso a la tecnología para permitir en los estudiantes y docentes no solo un acercamiento con la herramienta sino una verdadera apropiación.

El uso de REA, permite adquirir habilidades en la medida en que se interactúe con ellos. Al respecto, Sánchez (2008) clasifica las habilidades digitales en tres niveles:

1. Básico: Hace referencia al conocimiento con relación a ficheros y archivos, procesador de palabras, hoja de cálculo, presentador de transparencias, archivos con formato PDF, videos).

2. Medio: Habilidades para uso de correo electrónico, navegación y búsquedas por Internet, laboratorios virtuales y elaboración de material multimedia.

3. Superior: Habilidades para el desarrollo de software, bases de conocimiento, bibliotecas personales digitalizadas.

Está claro que estas habilidades se adquieren en forma ascendente, partiendo de un nivel básico, hasta llegar al nivel superior, donde en contextos con pocos recursos tecnológicos se inicia desde el nivel básico, por tanto es igual de importante que estas habilidades sean adquiridas por el docente, antes de emplear el REA con sus estudiantes. 
Sin embargo, antes de adquirir las habilidades se debe ser competente para ello. Las principales competencias que deben desarrollar los docentes al usar REA, entre otras son: organizar y animar situaciones de aprendizaje, elaborar y hacer evolucionar dispositivos de diferenciación, implicar a los alumnos en sus aprendizajes , trabajar en equipo, participar en la gestión de la escuela, informar e implicar a los padres, así como utilizar las nuevas TIC (Díaz, 2008). Es decir, abrir espacios para el aprendizaje con los estudiantes y padres de familia, para lograr la interacción y apropiación de estas herramientas.

En relación con ello, un REA posee características importantes las cuales van a lograr un óptimo alcance de los objetivos propuestos al hacer uso de ellos en ambientes educativos. Los REA dentro de sus características poseen un sujeto específico, un contenido unidad, un objetivo, y varios descriptores, esto con el fin de promover su reutilización y apoyar la interoperabilidad, accesibilidad y continuidad de uso con el tiempo (Burgos y Ramírez, 2013). Las características más importantes de los REA, parten de su capacidad para ser reutilizables, de fácil acceso y manejo de acuerdo con los medios que se vaya a emplear y a sus objetivos. Los REA permiten el acercamiento y aprovechamiento de la tecnología por parte de los estudiantes y docentes.

De igual manera, el uso de REA no solo promueve la adquisición de nuevos conocimientos, sino el refuerzo de los ya existentes. Por ello, Burgos y Ramírez (2011a) son quienes consideran importante proveer mecanismos que incentiven el aprovechamiento del conocimiento previo, a través de prácticas educativas abiertas. Es decir, realizar actividades académicas que le den relevancia al aprendizaje que ya se tiene, no para 
desmeritar la estrategia con que fue adquirido, sino para reforzarlo por medio de recursos innovadores.

2.2.2 Tipos de Recursos Educativos Abiertos. Existen REA útiles para el contexto educativo y que contribuyen a crear ambientes innovadores dentro del aula de clases. Para Glasserman, Mortera y Ramírez (2013) estos se identifican como cursos completos, materiales de cursos, módulos, libros, videos, exámenes, software y cualquier otra herramienta, materiales o técnicas empleadas para dar soporte y acceso al conocimiento, los cuales permiten un acercamiento del estudiante con la tecnología, debido a su interacción y aplicación en diferentes entornos o áreas y que debido a su variedad, pueden ser adaptados y reutilizados.

Los REA son recursos de fácil adquisición que se convierten en el complemento perfecto de los procesos de enseñanza - aprendizaje. Sin embargo, algunos de ellos deben ser adaptados o transformados según el contexto. Para Wilson (2008) y Wiley (2007) es importante esta adaptación pero coinciden en que no todos los recursos pueden transformarse debido a que no son editables o cuando no se cuenta con la herramienta tecnológica necesaria, no se pueden descargar o no se pueden ver en línea. Está claro que cuando un REA no cumple con las normas difícilmente puede ser reutilizado o adaptado según los objetivos para lo cual se haya pensado.

En el fondo, el alumno es el usuario más importante de los REA porque es él quien a través de su interacción va a demostrar si se han cumplido las expectativas y objetivos con su uso. Los profesores pueden actuar para adoptar y utilizar los REA de tal forma que estos ayuden a modificar sus prácticas educativas y lograr mayor productividad del recurso 
llevándolos a diferentes contextos (McAndrew, 2011), pero al alumno los REA le van a proporcionar un vínculo más directo hacia los recursos, su interacción con ellos y su aplicación.

Sin embargo, las escuelas rurales están en contextos diferentes, en donde los contenidos de los REA pueden estar alejados de sus expectativas. Por ello, Hepp, Hinostroza, Laval y Rehbein (2004) mencionan el caso de niños rurales en quienes es frecuente encontrar intereses por temas relacionados con actividades que realizan constantemente, o de las cuales han desarrollado ciertas habilidades como la pesca o la agricultura, o en caso de estudiantes o maestros indígenas quienes pueden no encontrar contenidos realizados en su lengua natal. Según lo anterior, sería el docente quien tiene la labor de adaptar los REA según las necesidades del contexto, abrir espacios para que estas comunidades interactúen y también sean ellos quienes con el tiempo puedan crear sus propios recursos, adaptados a su entorno y a sus intereses.

Está claro también que los REA deben ser evaluados con la intención de documentar el éxito o áreas de oportunidad tras su uso. Según la UNESCO (2011), se deben desarrollar habilidades para evaluarlos. Para iniciar es recomendable conocer más acerca de los REA a través de la exploración de los mismos, buscándolos en portales confiables y determinando su utilidad. Los docentes pueden encontrar REA útiles para la reflexión y la mejora de su propio plan de estudios y la pedagogía. Tal exploración permite desarrollar confianza para compartir recursos nuevos y/o adaptados a su plan curricular. Pero al querer hacer uso de un REA, es primordial saber evaluarlo debido a que pueden existir varios pero ante todo se debe tener en cuenta el contenido del mismo, así como su aporte a los objetivos que se 
quieren alcanzar con el uso del recurso. No simplemente es escoger uno al azar y emplearlo, se trata de explorar el REA y conocerlo a fondo.

2.2.3 Innovación con Recursos Educativos Abiertos. En el contexto educativo los procesos de enseñanza aprendizaje, pueden estar encaminados hacia estrategias innovadoras. Para ello, es Cobo (2007) quien plantea la innovación como un principio orientado al cambio que se sustenta en la incorporación de nuevas ideas, para construir conocimiento apoyado en el aprendizaje, la experimentación y las particularidades de cada contexto. En efecto, la innovación está orientada al cambio y a la experimentación con nuevas y diferentes herramientas tecnológicas que permitan mejorar las prácticas educativas.

Es necesario que no solo los docentes y alumnos estén dispuestos a innovar, sino que también se debe involucrar a los padres de familia y demás comunidad de acuerdo con los intereses que presenten. El Instituto Internacional de Planeamiento de la Educación (IIPE) y la Organización de la Naciones Unidas para la Educación, la Ciencia y la Cultura (UNESCO), participaron como coordinadores en un proyecto llamado INTEGRA en el cual hacen referencia a que la innovación requiere que las escuelas estén puestas a asumir un cambio en su estructura. Las instituciones educativas se comprometan a explorar si tienen la capacidad para involucrarse en una transformación de tales características en donde tomar riesgos sea un componente de la innovación, y que el error sea un elemento necesario para progresar. Es decir, riesgo de emplear herramientas de innovación dentro de los procesos de aprendizaje y que estas no cumplan con lo previsto y error, porque si no 
funcionan, se avanza en el conocimiento de las mismas y permite escoger las herramientas con mayor selectividad.

Pero cuando los recursos no cumplen con las expectativas y se usan solo por el hecho de llevar a cabo una herramienta diferente a las clases se pierde la intención y el sentido de ésta, convirtiéndola en un recurso distractor. Es más, Blackall (2008) afirma que:

Las organizaciones educativas deben desarrollar capacidad entre el personal y los estudiantes para acceder, crear, modificar y redistribuir el REA, y para participar en ellos socialmente en red. El desarrollo de habilidades y prácticas en este sentido va a mejorar la eficiencia y la calidad de su enseñanza y aprendizaje (p.9).

Por ello, el autor se refiere a evitar crear o usar REA con algún tipo de fallas tales como calidad de sonido, derechos de autor, desactualización o exceso de información innecesaria. Estos errores son comunes cuando la institución no abre espacios de capacitación a los docentes o cuando el docente no toma la iniciativa de involucrarse en el mismo.

Es decir, que para innovar, no sea sólo el docente en el aula quien implemente la herramienta, sino que desde el diseño curricular, los planes de área y diversos proyectos institucionales, se tengan en cuenta estas herramientas tecnológicas con las cuales se va a lograr una amplia acogida. Es así como Celaya, Lozano y Ramírez (2010) hacen referencia a la innovación en cuanto al conocimiento y manejo de los recursos tecnológicos como elementos que apoyan el trabajo docente, así como a la búsqueda y selección de las herramientas para que estas sean adaptadas a las necesidades, la organización y planeación de las actividades y la capacidad de emplear el conocimiento y experiencia en el uso de 
REA en otros contextos o en el diseño y aplicación de otras herramientas. Así las cosas, la institución debe contar con un curriculum flexible que permita llevar a cabo la innovación tecnológica desde un ámbito de calidad.

Dentro de los ambientes de aprendizaje es importante innovar con herramientas atractivas para los alumnos y que contribuyan a la construcción de conocimiento. Según Burgos y Ramírez (2011b) la nueva tecnología se presta a la construcción conjunta de significados, el trabajo colectivo en proyectos de interés por los alumnos, el desarrollo solidario de nuevos conocimientos y el uso simultáneo de múltiples medios para lograr objetivos comunes de alto valor comunitario. En cualquier caso, cada herramienta tecnológica que haga parte de los procesos educativos se debe convertir en un escalón más hacia la educación de calidad.

La innovación en los ambientes de aprendizaje tiene que ver con la forma en que se hace uso de REA, debido a que si se tienen claros estos aspectos, se va a hacer más fácil desarrollar actividades encaminadas hacia los intereses de los estudiantes y que permitan así una eficacia en los resultados que se pretenden alcanzar con estos REA. Por su parte, Gunn, Woodgate y O'Grady (2005) describen el modelo de proceso de la introducción de las nuevas tecnologías, a través de los siguientes pasos: percibir la utilidad, la participación temprana participativa, pruebas piloto, aceptación, introducción, uso y cambio organizacional y desarrollo. Así las cosas, estos pasos toman una dirección desde los objetivos de uso, pasando por la aplicación, para finalmente llegar al planteamiento de mejoras. 
Si bien es claro, la labor de un docente dentro del aula resulta ser dispendiosa y amerita la dedicación de tiempo para la preparación de las clases. Al respecto, Ramírez (2012) hace claridad en cuanto a que los REA reducen el tiempo de preparación de clases, todo depende de encontrar un recurso que esté acorde a las expectativas y que sea de fácil aplicación. Es decir, estos recursos bien buscados y bien utilizados permiten un aprendizaje significativo del estudiante y logran motivarlo a que mediante el uso e implementación de nuevas herramientas, en este caso las tecnológicas, se puedan desarrollar procesos de construcción de aprendizaje, los cuales despierten el interés y agrado de cada uno de ellos hacia las actividades académicas dejando de lado los malos hábitos escolares.

Dentro de un contexto como el rural, el uso de REA podría traducirse en un gran paso hacia la innovación, pero aún se evidencia una brecha digital. Cabero (2004, p.2) la define como "la diferenciación producida entre aquellas personas, instituciones, sociedades o países, que pueden acceder a la red, y aquellas que no pueden hacerlo". En otras palabras es la desigualdad de posibilidades que hay para acceder a la información, al conocimiento y la educación mediante nuevas tecnologías. Por eso se hace pertinente acercar más a la comunidad educativa a estos avances, a través de la alfabetización, debido a que la comunidad estudiantil se va a enfrentar a una nueva herramienta que tal vez no conozca o que haya usado poco. Incluso, trabajar con TIC, no supone tener las herramientas tecnológicas y usarlas de vez en cuando, implica plantear objetivos claros y actividades significativas que complementen acertadamente este nuevo proceso, ya que no se puede dejar de lado pues la educación hoy en día implica el uso de TIC. 
Además, la educación rural merece contar con las mismas oportunidades de la educación urbana, eficaz y con recursos de aprendizaje innovadores. La educación rural, debe contar con directrices que permitan introducir estrategias pedagógicas encaminadas a la calidad, gestión y fortalecimiento de habilidades entre directivos y docentes, con inclusión de la familia en los procesos educativos (Muñoz y Sanhueza, 2006). Mejor dicho, sea cual sea el contexto, la educación debe permitir igualdad en desarrollo de capacidades y habilidades del estudiante en la construcción y fortalecimiento de su propio aprendizaje.

\subsection{Investigaciones relacionadas con apropiación tecnológica y Recursos Educativos}

\section{Abiertos}

Son varias las experiencias que a nivel mundial existen con respecto a la apropiación tecnológica y recursos educativos abiertos. Estos antecedentes son un referente para identificar elementos relevantes de las experiencias de otros autores. En el siguiente apartado se recopilan algunas de ellas, cuyos aportes serán tenidos en cuenta para el proceso de investigación del presente proyecto.

\subsubsection{Investigaciones relacionadas con el tema de apropiación tecnológica. Entre} las investigaciones relacionadas con la apropiación tecnológica dentro de las aulas de clases, está la realizada por Andión (2010), cuyo objetivo principal fue la incorporación y apropiación de las TIC en las escuelas públicas de educación básica, no sólo para reducir la brecha tecnológica, sino la brecha cultural, económica y social que existe entre las comunidades rurales del sur y las urbanas del norte de México. De ahí que surgió la inquietud de si se requiere de la tecnología digital para resolver los problemas de acceso, calidad y equidad de la educación en México. El trabajo de campo se realizó durante los 
meses de septiembre y octubre de 2009, por un período de ocho días. Un equipo de 28 investigadores visitó a cada una de las escuelas seleccionadas y aplicó una conjunto de diez instrumentos de recolección de información: entrevistas a profundidad, conversaciones, observaciones, encuestas y actividades lúdicas de índole proyectivo, llevadas a cabo con los directores, maestros y alumnos de las escuelas primarias y secundarias públicas de nueve estados del país, lo que arrojó un cuerpo de datos objetivado en discursos orales, escritos, icónicos y audiovisuales. En otras palabras, se evidenció la diversidad de realidades que se superponen en el ámbito educativo y la complejidad de los procesos que se derivan al insertarse las TIC en el contexto escolar.

Sin embargo, se hace mención a una segunda investigación centrada en la apropiación tecnológica y es la realizada por Heredia, Escamilla y Gómez (2006), con la cual se determinó el impacto que los materiales multimedia mediados por computadora tienen sobre el desempeño en ciencias naturales y en las habilidades cognitivas de estudiantes de $3^{\circ}$ a $4^{\circ}$ grado de escuela primaria multigrado y en la que se tuvo en cuenta una muestra de sesenta (60) estudiantes de cuatro escuelas multigrado de básica primaria del sector rural indígena, con las cuales se aplicó una metodología basada en un grupo control y un grupo experimental. Los alumnos elegidos en el grupo experimental fueron llevados a una sala de cómputo para que interactuaran con los materiales, mientras que los alumnos del grupo control no fueron expuestos a los materiales. Antes y después del tratamiento fueron aplicadas pruebas de ciencias naturales y de habilidades cognitivas para establecer las diferencias entre los dos grupos y arrojó cómo resultados que el grupo experimental obtuvo un desempeño superior a diferencia del grupo control gracias al uso de materiales 
multimedia. Aparentemente, los materiales multimedia tendrían mayor impacto en la enseñanza de las ciencias naturales para los grupos más desfavorecidos. Lo cual es un indicio favorable como aporte para la presente investigación.

Para finalizar, y sin restarle importancia, se encuentra una investigación que buscaba qué variables afectan a la decisión final del educador para integrar la tecnología en su enseñanza y fue realizada por Mueller (2009) quien empleó una muestra de 185 profesores de primaria y 204 profesores de secundaria, con el fin de ofrecer un amplio resumen de las características del maestro y las variables que discriminan a los profesores que integran la tecnología de los que no lo hacen. La metodología que se implementó fue la realización de tres estudios con los profesores que integran y los que no integran la tecnología en sus aulas de clase. Se identificaron variables como experiencias positivas con las computadoras, comodidad del profesor con las computadoras, creencias específicas acerca de la tecnología informática como una herramienta de instrucción, capacitación, desafío, el apoyo y la eficacia de la enseñanza, del cual se hizo evidente que los maestros de primaria siguen luchando con algunas dificultades técnicas en el uso de la tecnología y una parte de estos docentes todavía no la están implementando, mientras que los profesores de secundaria fueron capaces de comprender la interacción entre los contenidos, la pedagogía y la tecnología, lo que hizo evidente que las barreras en la implementación de las tecnologías en clase vayan desapareciendo y lograran con esto mejorar sus practicas educativas.

\subsubsection{Investigaciones relacionadas con algún otro elemento de los Recursos}

Educativos. Algunas de las investigaciones realizadas acerca de la implementación de REA dentro de las prácticas educativas, evidencian la importancia de seguir realizando 
investigaciones que involucren estos elementos, debido a la eficacia que se ha demostrado con su uso. Es así que Mortera (2011) describe los resultados de un proyecto de innovación educativa que llevó a una metodología de búsqueda y adopción de REA útiles para la práctica docente así como mejorar las habilidades digitales de profesores de nivel de educación básica, media superior y superior, apoyado en los aportes de 241 maestros de diferentes niveles educativos de tres estados de México que compartieron sus experiencias prácticas en el uso e implementación de este tipo de recursos en sus salones de clase y a distancia. Se realizaron observaciones participantes, entrevistas cualitativas a profundidad y se aplicó un cuestionario. En resumen, los resultados que arrojó fue que los maestros participantes en su mayoría conciben los REA, como un recurso que puede ser usado libremente en educación en donde predomina el uso de REA en formato de texto seguidos por los de video y los docentes acostumbran utilizar los REA al final de la clase como medio de evaluación o refuerzo, aspecto clave que se tuvo en cuenta dentro de esta investigación.

En cambio, otro estudio importante relacionado con el uso de REA y que aportó ideas valiosas, es el realizado por García, Glasserman, Lascares y Perales (2010) quienes se centraron en la búsqueda de los beneficios para los alumnos cuando adoptan REA a sus practicas educativas. Para ello, se eligieron casos con diferentes características y entornos en los cuales cada docente adoptó un REA de acuerdo con la temática del curso y estos fueron puestos a disposición de los estudiantes para incorporarlos a la estrategia. Emplearon una metodología descriptiva y aplicaron instrumentos como la observación, las entrevistas y cuestionarios con estudiantes que presentan diversas relaciones con la 
tecnología y otros que están vinculados a prácticas con métodos tradicionales, del cual se concluyó que gracias a la adopción de éstos, hubo buen cambio en los procesos de enseñanza aprendizaje así como el aumento en el interés de los alumnos haciendo los contenidos más fructíferos tanto en línea como presenciales, además de la identificación de nuevos retos para tener en cuenta a la hora de hacer uso de REA en el aula. Pues bien, este estudio se convierte en un referente para el tema investigado debido a que sus objetivos están correlacionados.

El Tecnológico de Monterrey se ha caracterizado por la aplicación de proyectos y estrategias innovadoras basadas en la aplicación de las tecnologías en los procesos de enseñanza aprendizaje. Entre sus investigadores se encuentran Mortera y Burgos (2010) quienes mencionan el desarrollo de una iniciativa educativa, que se llama Temoa (antes Knowledge Hub), la cual se concibe por las necesidades de encontrar materiales eficaces en la enseñanza y el aprendizaje. En este proyecto participaron seis instituciones de educación superior contando con la representación de profesores e investigadores, los cuales trabajaron de manera virtual y presencial para crear un sitio web y motor de búsqueda académica en Internet, en donde estos REA son registrados y clasificados tras un proceso de aseguramiento de la calidad. La metodología empleada fue a través de mecanismos de comunicación como páginas web, foros de discusión, videoconferencias, chat, entre otros. Dentro de los resultados se encontraron barreras de acceso para el uso de REA en México por los maestros en las escuelas participantes como lo fue:

“...la infraestructura tecnológica (falta de acceso a internet, proyectores y computadoras), asuntos legales (acceso de los recursos en términos de licencias), la 
pertinencia del contenido de los materiales disponibles en Internet (principalmente recursos de otros países), la falta de recursos en español (problemas de idioma), la brecha de la alfabetización informática en las escuelas y la falta de conciencia en el ámbito institucional (falta de información en el nivel directivo". (Mortera y Burgos, 2010, p. 5).

Dichas barreras se hacen evidentes en varios contextos, entre ellos el que fue objeto de estudio en la presente investigación. A propósito de estas barreras y que es importante tener en cuenta para paliarlas, autores como Clements y Pawlowski (2011) realizaron un estudio para identificar el comportamiento del usuario, las actitudes y requisitos de calidad hacia los REA. La metodología empleada fue basada en un enfoque cuantitativo mediante la aplicación de encuestas con preguntas de opción múltiple y abierta, para conocer las opiniones de los maestros usuarios de los REA. Los resultados de estas encuestas indicaron que prevalece la búsqueda de REA por temas, así como la búsqueda de mecanismos de confianza ya sea por recomendación de algún colega o porque las organizaciones en donde están realizando la búsqueda del recurso, cuentan con buen prestigio. De igual manera fue evidente que los profesores encontraron pocos obstáculos para la búsqueda y reutilización de los REA dentro del ámbito nacional, pero al dirigirse a búsquedas internacionales hubo más barreras en cuanto a la compatibilidad del currículo, derechos de autor o cambios de temática, por lo cual muchos profesores participantes se limitaron a la búsqueda y reutilización de REA sencillos. En cuanto a la calidad de los REA, los profesores usuarios describieron que los recursos eran de calidad porque tenían un buen uso de multimedia en 
cuanto a animaciones y simulaciones, o porque se acomodaban al currículo de la institución o simplemente por el hecho de provenir de organizaciones con buena reputación.

Así las cosas, está claro que el uso de los REA dentro de los procesos educativos involucran aspectos como el origen, la temática, la estructura o el tipo de alcance o uso que el profesor le quiera dar dentro del aula de clases, como lo mencionan Clements y Pawlowski (2011) y de acuerdo con esto se podrá determinar si el REA es de calidad y que va a generar una adecuada apropiación de las tecnologías por parte del estudiante. Sin embargo, aún existen barreras que limitan estos usos como lo es el difícil acceso en zonas donde aun se presenta una brecha digital, o cuando los recursos no se muestran de manera que el estudiante y profesor, encuentre fácilmente lo que busca, sin gastar horas en encontrar el material adecuado (Contreras, 2010). Es decir los REA deben ser de fácil acceso para lograr que puedan ser utilizados eficazmente, pero aun así es necesario abordar la problemática que tienen muchas instituciones rurales que no cuentan con los recursos necesarios para acceder a herramientas tecnológicas y en las que las entidades gubernamentales no contribuyen eficientemente a dar solución a la misma.

En conclusión, las investigaciones mencionadas apuntan a que el uso de REA dentro de los procesos de enseñanza y aprendizaje, permiten mejorar la calidad educativa, aparte de que se convierten en un aliado vital para los maestros en sus clases, no solo porque permiten al estudiante involucrarse con herramientas innovadoras, sino porque son recursos diseñados para contribuir a la construcción del conocimiento. En el siguiente capítulo se abre paso a la metodología de investigación en la cual se mencionan los aspectos claves del contexto en el cual se llevó a cabo el presente estudio y el desarrollo del mismo como el 
método de investigación, la situación educativa, población y muestra, fuentes de información, técnicas de recolección de datos, prueba piloto, aplicación de instrumentos y la captura y análisis de datos. 


\section{Capítulo 3. Metodología General}

En este capítulo se aborda la metodología general del estudio, cuyo objetivo fue analizar el desarrollo de la apropiación tecnológica en alumnos de tercer grado de educación básica de una primaria rural, con un ambiente de aprendizaje que integró recursos educativos abiertos de contenidos en el área de matemáticas de operaciones básicas (adición, sustracción, multiplicación y división), solución de problemas, lectura y escritura de números; con el fin de contribuir con la innovación en los ambientes de aprendizaje de educación básica en contextos rurales. Para ello se presentan los siguientes apartados: método de investigación, población y muestra, temas, categorías e indicadores de estudio, fuentes de información, técnicas de recolección de datos, prueba piloto, aplicación de instrumentos y captura y análisis de datos.

\subsection{Método de investigación}

La metodología general de esta investigación se basó en un análisis cualitativo con un enfoque de estudio de casos, cuya pregunta de investigación fue ¿Cómo se desarrolla la apropiación tecnológica en los alumnos de educación básica primaria rural al trabajar con recursos educativos abiertos? Se optó por esta metodología debido a que permite hacer observaciones directas, entrevistas y examinar un caso en particular que se esté evidenciando dentro del contexto estudiado. Según Yin (2006) la base del método del caso es su capacidad para analizar a fondo un caso de la vida real. Es decir, este tipo de estudios es pertinente cuando se pretenden buscar respuestas a interrogantes específicos de un contexto con necesidades. 
Dentro de la presente investigación fue pertinente el uso del estudio de casos porque se buscaba realizar un análisis cualitativo a una situación presentada dentro de una institución pública de tipo rural. De acuerdo con Ramírez (2013a) la metodología de estudio de casos permite un acercamiento al objeto de estudio y examinarlo a profundidad a partir del análisis intrínseco (conocer a profundidad), instrumental (estudio de un caso como instrumento para conocer otro aspecto) o colectivo (elegir un caso entre varios). Por ello, se hizo pertinente analizar el caso propio de cada estudiante frente al uso de las herramientas tecnológicas en clase, teniendo en cuenta el poco acercamiento que ellos habían tenido con la tecnología.

\subsection{Descripción de la situación educativa}

Dentro de la presente investigación se trabajó con contenidos en el área de matemáticas para el tercer grado de educación primaria, debido a las dificultades que presentaban algunos estudiantes en esta área. El principal objetivo era acercar a los estudiantes a las matemáticas de una manera divertida y atractiva donde pudieran interactuar con herramientas tecnológicas como la computadora y así mejorar su desempeño académico. Los contenidos tratados fueron operaciones básicas (adición, sustracción, multiplicación y división), solución de problemas, lectura y escritura de números, entre otros. Para el desarrollo de estos contenidos se utilizó un recurso REA, que contenía el portal de educación zona alumnos de primaria de la junta de Castilla y León (2009), el cual presenta una serie de actividades interesantes, atractivas, lúdicas y sobre todo que permiten al estudiante interactuar de manera diferente con la construcción de su propio conocimiento, así como el uso de los REA GCompris y MathRapid, los cuales se 
evaluaron de forma cualitativa de acuerdo con las observaciones de las actividades realizadas por los estudiantes.

A continuación se muestra una propuesta pedagógica para el docente de primaria con el fin de contribuir a que el estudiante potencialice sus aprendizajes en el área de matemáticas a partir del uso de REA, hagan uso de diferentes recursos educativos para construir su conocimiento y demuestren interés hacia el aprendizaje de las matemáticas.

Objetivo del estudio: Que los estudiantes de tercer grado de primaria refuercen las cuatro operaciones básicas (adición, sustracción, multiplicación y división) y realicen cálculos mentales rápidos.

Estándares del eje temático: Adición, sustracción, multiplicación y división de números naturales partiendo de operaciones sencillas hasta las más complejas.

Procesos que se refuerzan: Uso de TIC, manejo de las matemáticas, agrado por la asignatura.

Recursos: Computadora portátil y escritorios de los estudiantes

Duración: Una hora mínimo por sesión.

- Primera sesión: Familiarización

Para iniciar, se realiza una etapa de familiarización en la cual los estudiantes hacen un reconocimiento de la herramienta y el REA que van a utilizar. En seguida, realizan ciertas actividades relacionadas con la planeación de la docente y que cuentan con un nivel de dificultad bajo que irá aumentando a medida en que avanzan las sesiones.

Recursos: Computadora portátil, REAs (GCompris y MathRapid)

Forma de trabajo: Grupal e individual 
Evaluación: No aplica

- Segunda sesión

En esta sesión se pretende que los estudiantes adquieran habilidades para realizar adiciones y sustracciones a partir de actividades de memoria individuales y contra la computadora. Esto les permite recordar operaciones o resultados de las tarjetas que ya se han descubierto y de paso agilidad en los resultados.

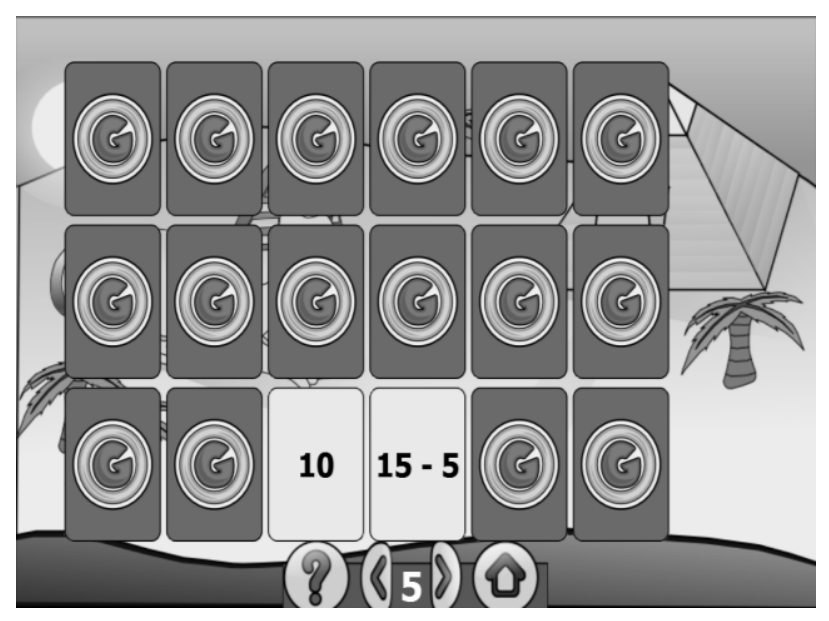

Figura 1. Actividades de memorización

Recursos: Computadora portátil, software descargado, espacio adecuado para el desarrollo de la actividad.

Forma de trabajo: Individual

Evaluación: Se hace de acuerdo a la observación de las actividades de cada estudiante.

- Tercera sesión

En esta sesión cada estudiante analiza la operación que le es suministrada y acomoda las cifras y los signos de tal manera que consiga el resultado. Se hace necesaria la 
orientación de la profesora con un ejemplo para que los estudiantes comprendan mejor la actividad. Con esta se espera que ellos logren aplicar diferentes operaciones en la búsqueda de una sola respuesta y mejorar su agilidad matemática.

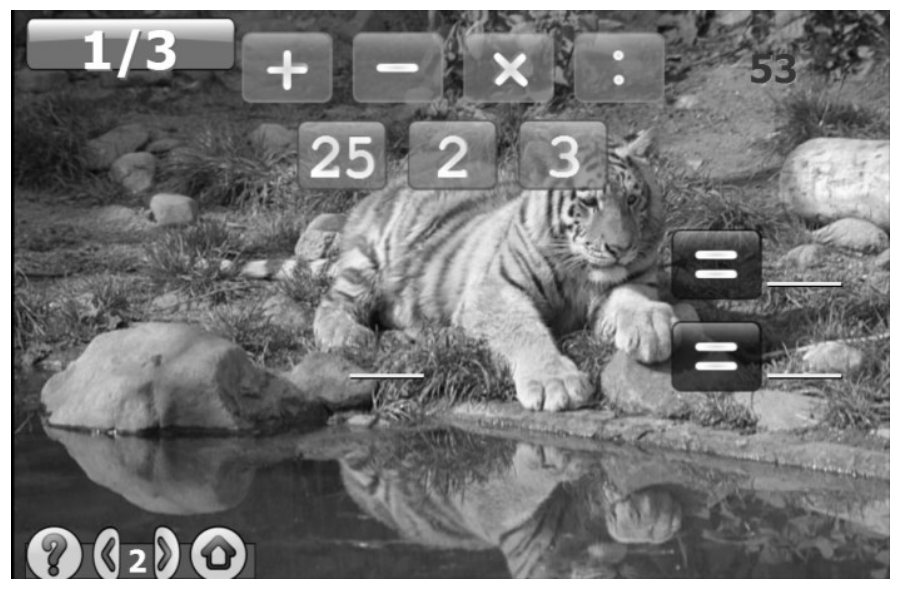

Figura 2. Actividades de combinación de operaciones

Recursos: Computadora portátil, software descargado, espacio adecuado para el desarrollo de la actividad.

Forma de trabajo: Individual y grupal

Evaluación: Cualitativa, de acuerdo con la observación de las actividades de cada estudiante y su avance en las mismas.

- Cuarta sesión

Se pretende que el estudiante agilice su proceso operacional a partir de actividades de descubrimiento y memorización, en la cual es importante la concentración para hallar la respuesta correcta. Se facilita un computador portátil por turnos a cada estudiante en el cual realizarán practicas por un tiempo para irse familiarizando con la herramienta y la actividad, luego se reúnen a los estudiantes y uno por uno realiza su actividad 
contabilizando el tiempo que gasta realizándola y así uno por uno para determinar quien lo hace correctamente en el menor tiempo posible o quien tenga más aciertos. Es importante aclarar al estudiante que el tiempo dedicado a estas actividades no es de desocupación, sino por el contrario es una actividad de clase que se debe tomar con seriedad.

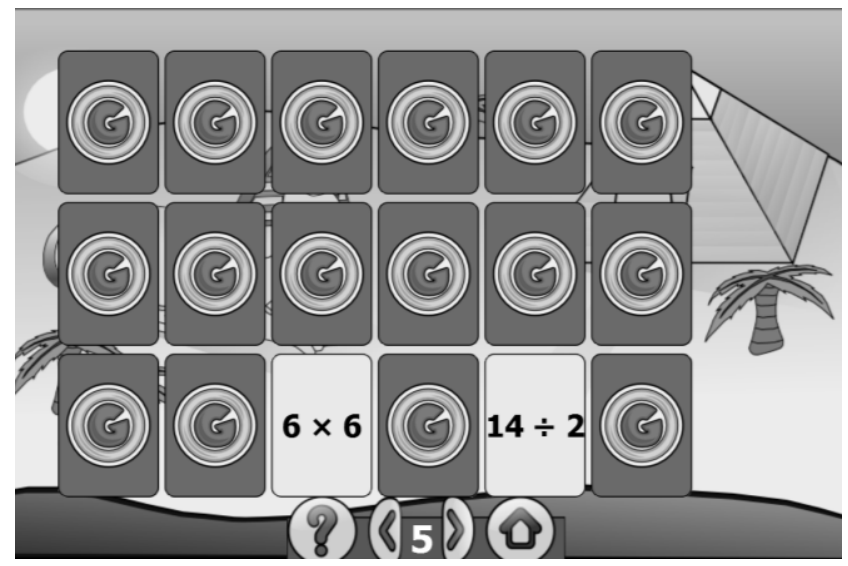

Figura 3. Actividades de memoria y descubrimiento

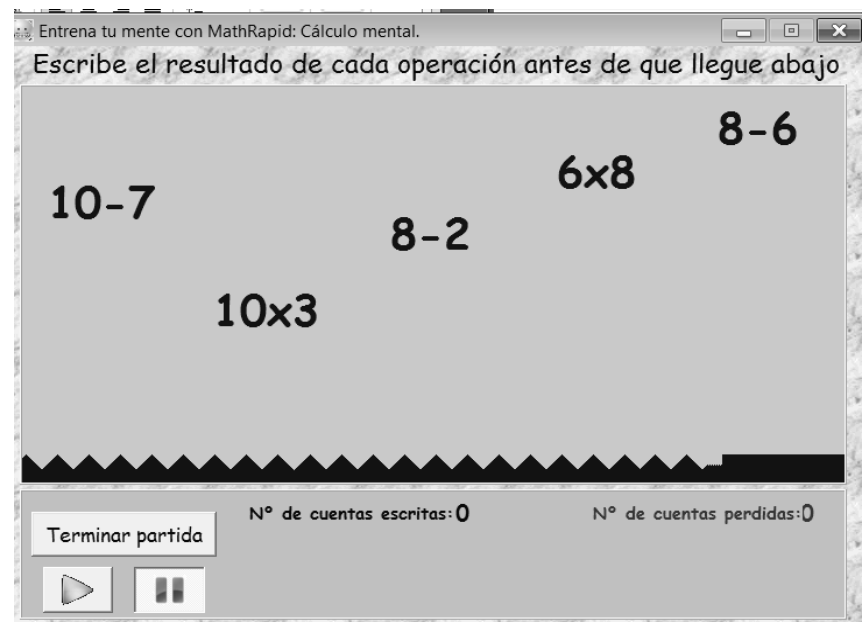

Figura 4. Actividades de agilidad

Recursos: Computadora portátil, software descargado, espacio adecuado para el desarrollo de la actividad.

Forma de trabajo: Individual y grupal 
Evaluación: Cualitativa, de acuerdo con la observación de las actividades de cada estudiante y su avance en las mismas.

- Quinta sesión

En esta sesión se espera que los estudiantes identifiquen lo múltiplos de un número natural. Para ello, la profesora da las indicaciones en el tablero sobre la forma de obtener los múltiplos de un número y cada estudiante por turnos en la computadora portátil realiza la actividad correspondiente en la cual debe seguir las instrucciones que la misma le indica como lo es usar las flechas del teclado para dar dirección al objeto verde hacia el múltiplo del número que muestra y así lograr identificar los múltiplos de cualquier número.

\begin{tabular}{|c|c|c|c|c|c|c|}
\hline \multirow[t]{6}{*}{ 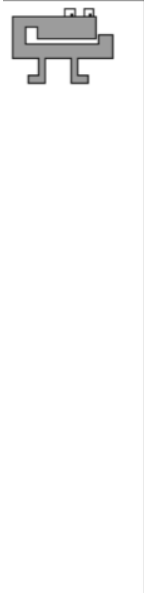 } & \multicolumn{6}{|c|}{ Múltiplos de 2} \\
\hline & 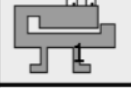 & 5 & 7 & 6 & 2 & 7 \\
\hline & 6 & 3 & 2 & 10 & 8 & 8 \\
\hline & 5 & 11 & 9 & 2 & 4 & 2 \\
\hline & 4 & 3 & 8 & 7 & 6 & 2 \\
\hline & 7 & 4 & 3 & 12 & 5 & 7 \\
\hline (8) (0) & 1 & 10 & 12 & 5 & 3 & 12 \\
\hline
\end{tabular}

Figura 5. Actividades de múltiplos de un número

Recursos: Computadora portátil, software descargado, espacio adecuado para el desarrollo de la actividad.

Forma de trabajo: Individual y grupal 
Evaluación: Cualitativa, de acuerdo con la observación de las actividades de cada estudiante y su avance en las mismas.

\subsection{Población y muestra}

Dentro de este estudio, la población total consistió en 19 alumnos pertenecientes a una institución de educación de nivel primaria del sector público rural, ubicada en el departamento de Santander, Colombia. La institución se encontraba ubicada a $12 \mathrm{Km}$ de la zona urbana por lo que pertenecía al estrato socioeconómico bajo, con dificultades para acceder satisfactoriamente a los recursos básicos. De acuerdo con Stake (2007) cuanto más intrínseco sea el interés de un caso, más se debe frenar la curiosidad y los intereses especiales y centrarse en los temas específicos. Por ello, se escogió una institución integrada con estudiantes de nivel preescolar y primaria, la cual comprendía la siguiente distribución de alumnos: 2 estudiantes de preescolar, 5 estudiantes de primer grado, 2 estudiantes de segundo grado, seis estudiantes de tercer grado, tres estudiantes de cuarto grado y un estudiante de quinto grado.

La elección de la muestra fue de tipo no probabilística por conveniencia de acuerdo con la propuesta de Merriam (2009), dado a que así estaban organizados los grupos en donde se tuvo acceso para realizar el estudio. De tal forma que se seleccionaron a tres estudiantes de tercer grado de primaria, los cuales representaban tres casos diferentes de aprendizaje, el caso de una alumna que repetía grado, un estudiante con diagnóstico médico de problemas de aprendizaje y un alumnos con antecedentes de acceso a tecnología. Asimismo, se consideró la participación de una docente a cargo de todos los grupos al tratarse de una escuela multigrado. 


\subsection{Tema, categorías e indicadores de estudio}

Dentro de la presente investigación se estudió el desarrollo de apropiación tecnológica con recursos educativos abiertos en el aprendizaje de educación primaria. De acuerdo con la temática, se identificaron a través de un cuadro de triple entrada, las categorías de estudio en las cuales se desglosa la temática a estudiar, así como los indicadores que son las preguntas que permiten llegar a las categorías (ver apéndice A). Según Creswell (1994) las preguntas deben ser formuladas delimitando el enfoque del estudio pero sin limitar al investigador y así estas preguntas se convierten en los asuntos a explorar en las entrevistas, observaciones, documentos y materiales de archivos. A continuación se exponen cada uno de las categorías con sus respectivos indicadores que hicieron parte de este estudio.

\section{Nivel de apropiación tecnológica}

Esta categoría fue importante debido a que permitió conocer cual era el dominio y habilidades de los estudiantes hacia la tecnología. Los indicadores que se definieron dentro de esta categoría fueron la familiarización, la utilización y la integración, reorientación y evolución de los recursos tecnológicos en el aula. Ésta buscaba determinar que tanto era el manejo que los estudiantes de este contexto rural le daban a la tecnología y de que manera esto permitía desarrollar habilidades y familiarizarse con los procesos de enseñanza y aprendizaje que estos permiten al hacer uso de TIC.

\section{Evaluación de los entornos con REA}

Para complementar la apropiación tecnológica en ambientes educativos, fue necesario centrarse en esta categoría en donde los REA se tradujeron en la herramienta tecnológica 
que llegó a innovar en el contexto que fue objeto de estudio. Dentro de esta categoría se definieron indicadores como tipos de REA utilizados, frecuencia de uso de REA y el impacto de éstos en los procesos de enseñanza - aprendizaje. Cada uno de estos indicadores se basó en determinar cuales REA resultaban más atractivos para los estudiantes al realizar sus actividades académicas, así como la manera en que se integran a dichas actividades y cómo permitían llegar a la construcción de conocimiento.

\section{Innovación con REA en ambientes educativos rurales}

Finalmente esta categoría también se constituyó como una parte esencial en la investigación, porque además de conocer cuales eran los niveles de apropiación y la evaluación de los contextos con uso de REA, era necesario investigar como era la innovación con REA en entornos rurales. Los indicadores presentes dentro de esta categoría fueron la planeación de las actividades con uso de REA, la aceptación de los REA en el desarrollo de las actividades y la alfabetización digital, debido a que se necesitaba estudiar como dentro del entorno rural la innovación tecnológica con REA daba paso a mejorar las estrategias de enseñanza y aprendizaje y a partir de la alfabetización digital se permitía ir cerrando la brecha digital y optimizar los niveles de aprendizaje.

\subsection{Fuentes de información}

Dentro de la presente investigación se hizo una revisión de literatura y a partir de los temas, categorías e indicadores de estudio, se plantearon las preguntas a las cuales se buscó dar respuesta con el desarrollo del estudio y cuyas fuentes precisas para suministrar las respuestas fueron los estudiantes y el análisis de actividades realizadas por ellos y por la docente. Las fuentes de información se seleccionaron porque estas deben permitir 
interpretar la información que se está recopilando y saber de inmediato si son las adecuadas para el estudio de investigación (Yin, 2009). Es decir, se escogieron estas fuentes debido a que la Institución educativa solamente dispone de una docente investigadora y se trabaja por multigrados, siendo los principales involucrados los estudiantes y las actividades que ellos realizan. Las categorías e indicadores que se revisaron en la docente y los estudiantes fueron: nivel de apropiación tecnológica, evaluación de los entornos con REA y la innovación con REA en ambientes educativos rurales basadas en qué tan familiarizados estaban con el uso de las TIC, así como las principales actividades en las que utiliza recursos tecnológicos y la forma en que esto incide para motivar a los estudiantes a aprender. De igual manera, fue importante determinar la planeación de las actividades, qué clases de REA se utilizaba, de qué forma se integraban a las actividades de clase y cómo estos ayudaban a la construcción de conocimiento.

\subsection{Técnicas de recolección de datos}

Las técnicas escogidas para la recolección de datos permitieron indagar dentro del contexto de la investigación para dar respuesta al problema planteado. Unas de las técnicas empleadas fue el registro de observación de las actividades significativas de los alumnos (ver apéndice B), y los trabajos de los alumnos resultado de la integración de REA, que permitieron indagar las siguientes categorías e indicadores: nivel de apropiación tecnológica (familiarización, utilización, integración), evaluación de los entornos con REA (tipos de REA utilizados, frecuencia de uso de REA, impacto en los procesos de enseñanza aprendizaje) e innovación con REA en ambientes educativos rurales (planeación de las

actividades con uso de REA, aceptación de los REA en el desarrollo de las actividades y la 
alfabetización digital), con el objetivo de llevar las anotaciones de las observaciones realizadas en cada clase y dejar un registro escrito de la actividad realizada, s descripción e interpretación.

Generalmente, estas anotaciones están temáticamente desordenadas, por lo que es recomendable que después de cada sesión de observación se trate de identificar como nombrar las acciones observadas en el salón de clase (Ramírez, 2007). Por ello, en esta investigación se hizo pertinente el uso de esta técnica porque permitió que el investigador llevara un continuo diario de anotaciones acerca de aquello que observaba en las clases y de la aplicación de REA lo cual se necesitaba para dar respuesta al problema de investigación, así como los trabajos de los alumnos resultado de la integración de REA.

Por otra parte, se encuentra un tipo de técnica que es la observación no participante en donde a través del diario del investigador se recopila la información necesaria (ver apéndice C), con el objetivo de conocer y analizar cada una de las actividades realizadas durante la aplicación del recurso. Ésta técnica permitió indagar las mismas categorías e indicadores que la técnica de registro de observación de las actividades significativas de los alumnos, nivel de apropiación tecnológica (familiarización, utilización, integración), evaluación de los entornos con REA (tipos de REA utilizados, frecuencia de uso de REA, impacto en los procesos de enseñanza aprendizaje) e innovación con REA en ambientes educativos rurales (planeación de las actividades con uso de REA, aceptación de los REA en el desarrollo de las actividades y la alfabetización digital).

Éste tipo de observación, supone que haya cierto distanciamiento del investigador respecto a los fenómenos de la realidad observada. Es decir, adopta un rol de espectador de 
la realidad sin realizar acciones que modifiquen el fenómeno que está observando (Yuni y Urbano, 2006). De igual manera a partir de la observación se pueden hacer inferencias y se pueden descubrir los patrones que conforman estos datos (Spradley y Baker, 1980). De ahí que fuera necesario llevar un registro en el diario de campo en donde se describiera e interpretara cada una de las actividades realizadas por los estudiantes y sus actitudes frente al uso de la herramienta tecnológica.

Una tercera técnica utilizada dentro de la investigación como recurso no menos importante que las anteriores es el cuestionario (Ver apéndice D), cuyas categorías indagadas fueron: nivel de apropiación tecnológica (familiarización, utilización, integración), evaluación de los entornos con REA (tipos de REA utilizados, frecuencia de uso de REA, impacto en los procesos de enseñanza aprendizaje) e innovación con REA en ambientes educativos rurales (planeación de las actividades con uso de REA, aceptación de los REA en el desarrollo de las actividades y la alfabetización digital). El cuestionario contiene 17 preguntas de opción múltiple, 16 de ellas con tres opciones de respuesta y una con cuatro opciones. Para Adame, Barriga y Navarro (2011) el cuestionario es un formulario que presenta un grupo de preguntas respecto a una o más variables que se van a indagar, haciendo uso de preguntas claras, sin palabras ambiguas o que puedan generan disgusto con el entrevistado. Es por ello que se empleó el cuestionario con el objetivo de tener un acercamiento con los entrevistados para generar espacios de confianza y obtener respuestas validas y confiables. 


\subsection{Prueba piloto}

Para asegurar la estructura y presentación de instrumentos se realizó una prueba piloto. Cabe mencionar que la prueba piloto se refiere a una aplicación experimental de la técnica de recolección a usar dentro de la investigación y que se hizo lo más real posible, aplicada solamente a una pequeña muestra con las características del grupo de estudio (García, 2004). La finalidad de la prueba era determinar si la técnica estaba acorde, clara y cumplía con los objetivos propuestos o si se debía mejorar para que al momento de llevarla a cabo con el grupo original se lograran los resultados esperados. La prueba piloto fue aplicada a los mismos estudiantes de la investigación, por tratarse de un grupo pequeño, además que generó más confianza al momento de determinar si los instrumentos eran acordes a lo que se pretendía obtener como resultado. Los resultados de la prueba piloto no sugirieron ninguna modificación mayor, debido a que inicialmente se había validado con expertos como la Dra. María Soledad Ramírez Montoya y por el Dr. Leonardo David Glasserman Morales, equipo docente del Tecnológico de Monterrey, al igual que se hizo una selección de las preguntas del cuestionario y los estudiantes se mostraron muy seguros al momento de responder e interesados por realizar las actividades de la investigación.

\subsection{Aplicación de instrumentos}

En la medida en que se busca recopilar la información pertinente para dar respuesta a la pregunta de investigación, es necesario llevar a cabo una aplicación de instrumentos basada en la veracidad de los mismos. Para Ramírez (2013b) es necesario apoyarse en la triangulación como elemento para ver la realidad desde puntos diferentes y que dan validez a los resultados. Es así, que esta investigación hizo uso de esta técnica, lo cual puede 
contemplarse con la revisión del cuadro de triple entrada (Ver apéndice A) donde se aprecian los cruces de instrumentos.

Inicialmente se solicitaron los permisos necesarios para llevar a cabo la investigación dentro del contexto establecido (Ver apéndice E y F), posteriormente se dio inicio a la observación y se registró a través del diario de campo, las situaciones presentes en el aula de clases con relación a las estrategias de aprendizaje utilizadas por los estudiantes. Estas observaciones se realizaron durante el desarrollo de las actividades escolares para no afectar o cambiar la intención de la misma. En la medida en que transcurrían los días se fueron llevando los otros instrumentos como el registro de observación de las actividades de los estudiantes en la cual se hacia uso de los REA, para determinar que sentido y aplicación se les daba a los mismos y como se desarrollaba su apropiación. El cuestionario se empleó en los inicios en que se dio el uso de los REA y al finalizar el estudio para determinar el avance que se había tenido y obtener mejores resultados.

\subsection{Captura y análisis de datos}

Una vez que se realizó la aplicación de los instrumentos de recolección de datos, es pertinente mencionar como fue la captura y análisis de los datos recogidos. A propósito, Merriam (2009) propone revisar inicialmente el objetivo del estudio para comenzar el análisis porque pueden saltar a la vista interrogantes como ¿qué hacer?, ¿por dónde empezar? o incluso sentirse abrumado ante la cantidad de datos. Es decir, teniendo claro cuál fue el propósito de la investigación, resulta más fácil el análisis de los datos.

Sin embargo, es pertinente aplicar estrategias que permitan llevar a cabo un buen análisis de datos sin caer en enredos o confusiones. Es Yin (2003) quien menciona tres 
principios de la recopilación de datos, el primero es utilizar diferentes fuentes de evidencia, luego crear una base de datos del estudio de caso y finalmente mantener un enlace entre las pruebas. Es por ello que se mantiene una organización y se permite un mayor entendimiento de lo que se va a analizar.

En esta investigación se inicio con el análisis de los datos obtenidos en las observaciones para luego compararlos con los del cuestionario para determinar la validez y confiabilidad de los mismos a la hora de generar resultados. Para Yuni y Urbano (2006) la confiabilidad es la capacidad que tiene el instrumento para arrojar los datos que correspondan a la realidad que se pretende conocer y eso depende de haber generado desde el comienzo las instrucciones claras y los procedimientos a seguir durante la recolección de datos). En ese sentido, en el presente estudio la confiabilidad se aseguró mediante la triangulación de fuentes metodológicas donde la información se obtuvo mediante diferentes técnicas de recolección de datos. Con respecto a la validez, Merriam (2009) hace alusión a dos tipos de validez, interna y externa, la primera relacionada en cómo los hallazgos obtenidos coinciden con la realidad y la segunda se refiere a cómo los resultados de un estudio pueden aplicarse a otras situaciones. En este estudio, la validez interna describe una situación real de lo que ocurre en un contexto como lo es el entorno rural y la aplicación de REA para el aprendizaje de contenido de matemáticas. En contraparte, la validez externa no permite que los resultados obtenidos se generalicen ya que se trató de un estudio acotado a un contexto, a cierto número de participantes, con cierto contenido.

Este capítulo ha dejado en evidencia la forma en que se pueden llevar a cabo estudios en contextos donde se presentan necesidades y cuyos participantes contaban con poca 
interacción con recursos tecnológicos. Fue así como a través de las técnicas de recolección de datos propuestos (cuestionarios, observaciones y registros) se obtuvieron los resultados del estudio guiados con las categorías e indicadores. En el siguiente capítulo se presentan los resultados del estudio y su análisis. 


\section{Capítulo 4. Resultados obtenidos}

En este capítulo se presentan los resultados obtenidos del estudio después de haber aplicado diferentes instrumentos de investigación mediante un enfoque cualitativo de estudio de casos, de acuerdo a cada una de las categorías e indicadores empleados como base para recolectar la información necesaria para dar respuesta a la pregunta de investigación. Las categorías de estudio fueron: nivel de apropiación tecnológica, evaluación de los entornos con REA e innovación con REA en ambientes educativos rurales.

\subsection{Presentación de resultados}

La información recolectada a partir del uso de diferentes instrumentos deja entre ver cómo es la apropiación de los estudiantes hacia las TIC y los REA. En la observación de la clase en la cual se utilizaron los REA se evidenció la forma en que se puede hacer uso de los mismos y su importancia en los procesos de aprendizaje de los estudiantes.

4.1.1 La clase con uso de REA. El aula de clases en donde se llevó a cabo el estudio, es de proporciones reducidas en la cual se albergan estudiantes de los niveles de preescolar y educación básica primaria hasta el grado quinto. Debido a estas descripciones se hizo necesario distribuir a los alumnos de forma tal que las actividades de los demás compañeros no fuesen un distractor para ellos o viceversa. Por ello, se ubicaron en la parte final del salón de clases como lo muestra la siguiente figura. Esta distribución permitió desarrollar de forma más eficaz las actividades. 


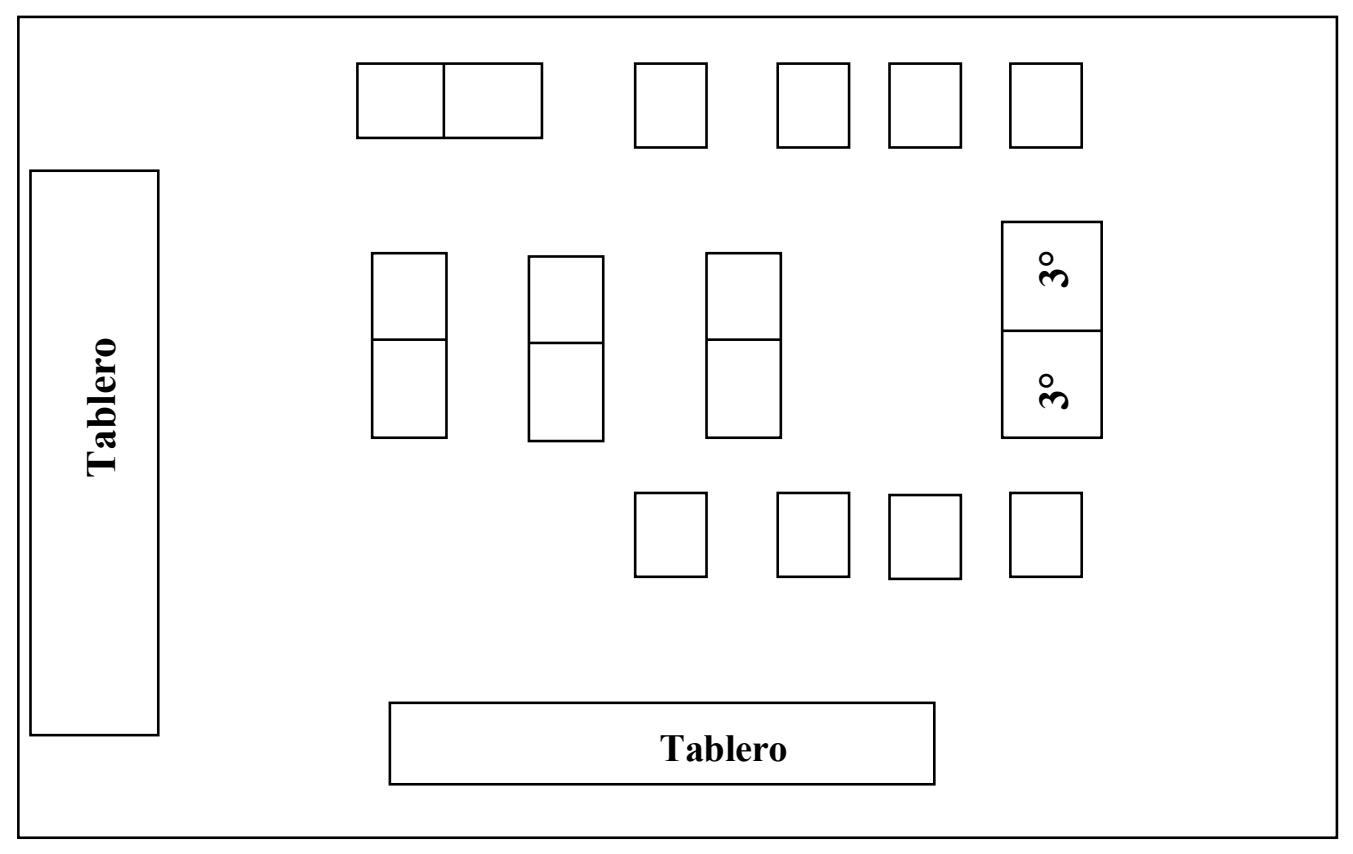

Figura 6. Distribución de los estudiantes en el aula de clases

La manera en que la profesora distribuye a los estudiantes en el aula de clases se debe a que es un aula multigrado y se cuenta con una sola área para dictar clases y una sola profesora para atender a 19 estudiantes. Al acercarse la profesora al escritorio de los estudiantes de tercer grado, les pide que presten mucha atención a las actividades que van a realizar con ayuda de la computadora. La cara de alegría de los niños no la podían ocultar y estuvieron atentos a las indicaciones. Primero, la profesora les preguntó: “¿Qué era esto?” señalando el computador portátil, a lo cual los estudiantes le respondieron en tono algo sarcástico y cómo si hubiesen preparado un coro: “ipues, un computador!”. La profesora inició así con una etapa de familiarización del dispositivo tecnológico que se pretendía utilizar.

La profesora comenzó a mostrarle a los estudiantes diferentes aplicaciones de la computadora, encendido, apagado, uso del mouse táctil, cámara web, entre otros, a lo cual 
se mostraban siempre atentos y asombrados. Luego de ir conociendo el equipo y manipulándolo, uno de ellos preguntó: “¿Vamos a jugar?”, a lo que la profesora inmediatamente le contestó: “iclaro, vamos a aprender jugando!”. Abrió el REA GCompris que ella con anticipación ya había explorado y escogido con detenimiento y dejó que ellos revisaran una a una las actividades que allí venían. Después de unos minutos, la profesora los organizó para que realizaran las actividades de cálculo que allí venían. Estas actividades eran de las cuatro operaciones básicas, adición, sustracción, multiplicación y división. Al comienzo al tratarse de agilidad mental, se confundían mucho y no lograban superar las actividades, de igual manera manifestaron a la profesora que su se le podía adaptar un mouse al computador porque con la "pantallita" refiriéndose al mouse táctil, se equivocaban mucho.

Sin embargo, al no poderse adaptar un mouse al portátil, los estudiantes siguieron realizando las actividades muy animados y compitiendo entre ellos para realizar las operaciones mentales más rápido.

4.1.2 Caso A. Este caso corresponde a un estudiante de 3er grado que lleva en la institución tres años y actualmente tiene 12 años de edad. Al ingresar a la institución presentaba un diagnóstico médico con déficit de aprendizaje, por lo cual no sabía leer, ni escribir correctamente. Con base en lo que la docente comentó, lo que le hacía falta al niño era exigencia porque, aunque presentaba dificultades en el aprendizaje, poco a poco las fue superando y ahora se le percibe un desenvolvimiento como a los demás niños. Su alegría al usar la computadora en las clases, era evidente. Aunque demostraba curiosidad, su desconocimiento y temor al tocar el dispositivo era innegable, pues su interacción con el 
mismo había sido poco. En el diario del investigador se registró como el alumno de tercer grado mostraba interés en el uso de la computadora a pesar de no haber tenido interacción previamente con ella.

\section{Familiarización e integración}

Durante el desarrollo de las sesiones planeadas para las clases de matemáticas a través del uso de los REA, se evidenció un estudiante interesado en la ejecución de las actividades pero inseguro en aquellos casos en que debía hacer uso de operaciones mentales rápidas o de las tablas de multiplicar, con las que ha tenido dificultades. Pero en la medida en que interactuaba con el REA, la confianza regresaba y su actitud mejoraba, así como sus resultados. En cada una de éstas sesiones, el nivel de dificultad que presentaba cada recurso iba aumentando lo que generaba en él una mayor motivación, aunque en momentos, al no encontrar de forma rápida y acertada la respuesta a la operación planteada, se sentía desanimado. Pero en esos instantes, sus compañeros lo animaban a continuar y en ocasiones le daban pistas sobre el paso a seguir y eso se convertía en un aliciente para él.

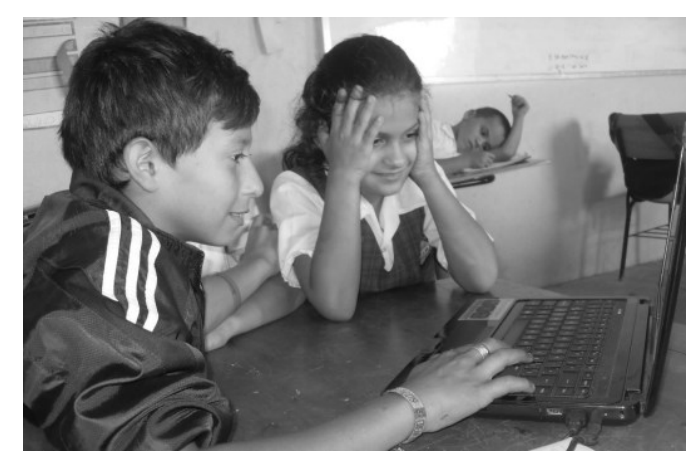

Figura 7. Estudiante resolviendo actividades con REA

Cuando la maestra le indicaba la actividad a realizar, el alumno mostraba temor ya manifestó que el ejercicio parecía difícil de realizar pero bastaba con una explicación para 
que comprendiera el objetivo de la actividad y la forma de realizarla. Al momento de contestar el cuestionario fue aún más sorprendente cuando la maestra indicó que se realizaría de forma virtual, que no se le entregaría en una hoja de papel con preguntas, sino que sería en un documento del programa Word donde se esperaba que se leyera cada pregunta y sombreara de color amarillo la respuesta que considerara pertinente.

\section{Aceptación de los REA en el desarrollo de las actividades}

Su cara de asombro era indiscutible: “¡No, yo no hago eso!”, “¡no sé cómo hacerlo!”. Eran unas de las expresiones que le manifestaba a su maestra, quien lo tranquilizó y le explicó que tecla usar para irse desplazando en el documento, así como el uso del mouse para seleccionar la respuesta y sombrearla de amarillo. Seguido a esto, sus actitudes mejoran y realiza sus actividades con más confianza.

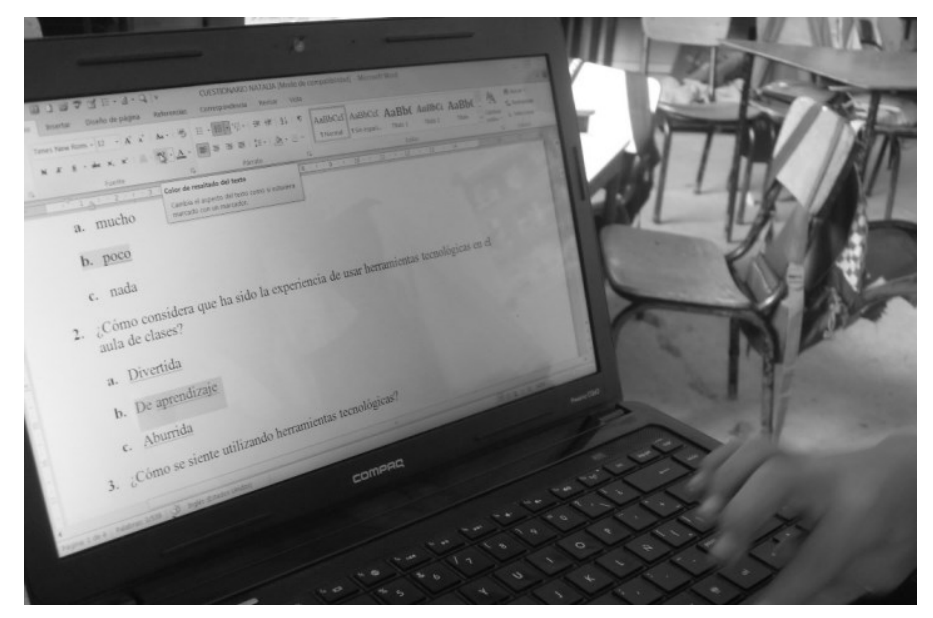

Figura 8. Estudiante resolviendo el cuestionario

Las observaciones a cada una de las sesiones realizadas por el estudiante indican que es más práctico y significativo realizar una clase con ayuda de REA. El mismo estudiante manifestó que: "fue muy interesante trabajar de esa forma con recursos porque aprendí 
muchas cosas", "me gustaría seguir usándolos", lo que confirma que en este caso, el uso de algunas herramientas TIC en clases contribuye a mejorar los procesos de enseñanza aprendizaje y demostrando así que ese estudiante alcanzó un nivel de apropiación tecnológica de integración y evolución.

4.1.3 Caso B. Este caso aborda la situación de una niña de 10 años que se encontraba en la institución desde los cinco años y que además repetía el curso de tercer grado. En el ciclo escolar anterior, su interés por la realización de las actividades era bajo por lo cual no logró superar el nivel esperado en el curso. En el nuevo ciclo escolar, aunque el resultado no es superior, ha mejorado notablemente su rendimiento, su responsabilidad, y desempeño. Ella es tímida, pero le gusta sobresalir ante sus compañeros y compañeras. También mostró agrado y empatía hacia la realización de las actividades con ayuda de la computadora.

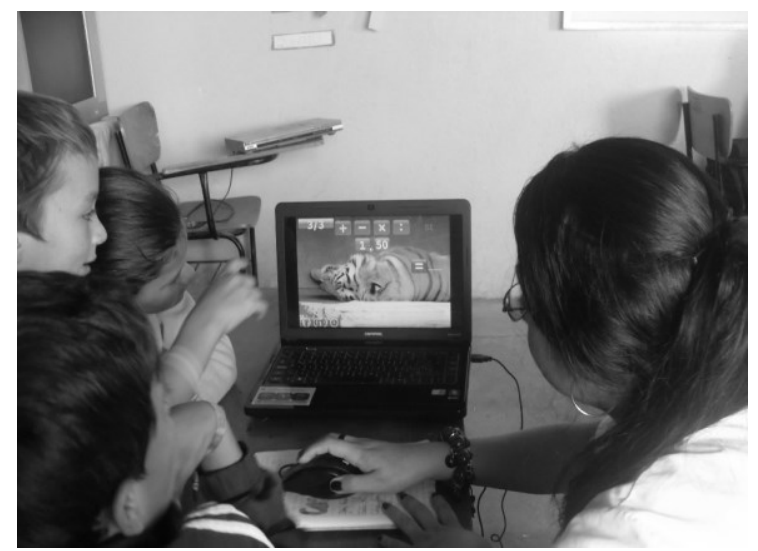

Figura 9. Estudiantes atentos a las explicaciones de la docente

\section{Familiarización}

La interacción de la alumna con la herramienta ha sido poca, pero aprende muy rápido y recuerda con facilidad los comandos que debe usar para cierta actividad, incluso 
orienta a sus compañeros. Durante la observación de sus actividades de matemáticas con el REA se evidenció una rapidez mental en la alumna al realizar las operaciones asignadas por el recurso, pero también se vio un afán por ganarle a sus compañeros y acertar en los resultados. A pesar que ha tenido dificultades con las multiplicaciones, se mostró animada y logró realizar las actividades correctamente.

\section{Utilización e integración}

En la medida en que avanzaba de actividad, ella siempre estaba a la expectativa de lo que iba a suceder o de lo que la docente les iba a explicar, incluso les pedía a sus dos compañeros que prestaran atención a las orientaciones. Cuando se llegó el momento de la sesión en que iban a conocer los múltiplos de un número, manifestó: “¡Uy se acabaron las multiplicaciones!”, “¿ahora que se hace?”. Fue evidente su desorientación pues creía que se había cambiado de contenido pero en realidad era relacionado con la multiplicación; una vez que se leyó la teoría que explicaba el contenido comprendió que se trataba y manifestaba que le parecía muy fácil. Inmediatamente la docente le explicó que así de fácil era aprender a multiplicar, pues los múltiplos de un número eran los mismos de las tablas de multiplicar que poco le gustaban. Incluso, terminada la sesión la docente le hizo una evaluación del tema y la aprobó.

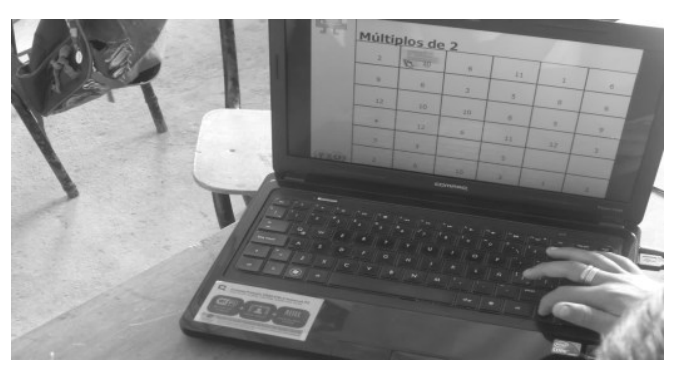

Figura 10. Actividad relacionada con los múltiplos de un número 


\section{Aceptación de los REA en el desarrollo de las actividades}

Cada actividad que realizó la alumna la hizo mostrando un interés y un agrado inexplicable. En ningún momento manifestó estar aburrida o desanimada, por el contrario, decía que le gustaba mucho y en el cuestionario al preguntarle con qué frecuencia es pertinente el uso de REA en las clases, su respuesta fue: "todos los días en cada clase". Cuando la docente le decía a los alumnos que guardaran todo lo que tuvieran sobre el escritorio, ella enseguida dirigía su mirada hacia el morral de la docente con una sonrisa en sus labios y le susurraba al oído a sus dos compañeros. Ya sabía que la profesora tenía la computadora portátil en el lugar.

Con la observación de cada una de las actividades realizada por la estudiante, se concluye que es una niña interesada en aprender y que sólo basta un poco de más atención para que comprenda lo que debe hacer adecuadamente, tal y como sucedió cuando la profesora le comentó que le iba a hacer unas preguntas sobre el trabajo que ha venido realizando en clases con ayuda de REA y le pidió que fuera lo más sincera posible. Ella sin titubear respondió afirmativamente, pero cuando la profesora le mostró el cuestionario virtual y le dijo que lo iba a responder sin ayuda, su actitud fue de temor y le decía: “¿no, profe pero eso cómo se hace?”, “¿yo no soy capaz?”. A lo que enseguida la maestra le indicó: “¡Claro que puedes!”, “¿no ves todo lo que has logrado?” “¡Yo te explicaré una vez cómo hacerlo y verás lo sencillo que es!’. Estas palabras fueron claves para generar confianza en la estudiante, quien con dos explicaciones inició a responder el cuestionario.

La profesora dejaba que la alumna trabajara sola pero la observaba sin que ella se diera cuenta y se evidenció la facilidad con la que comenzó a utilizar las teclas, el mouse y 
a resaltar la respuesta que ella consideraba pertinente. Fue una experiencia gratificante el detectar en los niños y niñas de escuela rurales, su agrado por aprender, por conocer y utilizar otras herramientas educativas como los REA. Su nivel de apropiación tecnológica fue de integración y evolución.

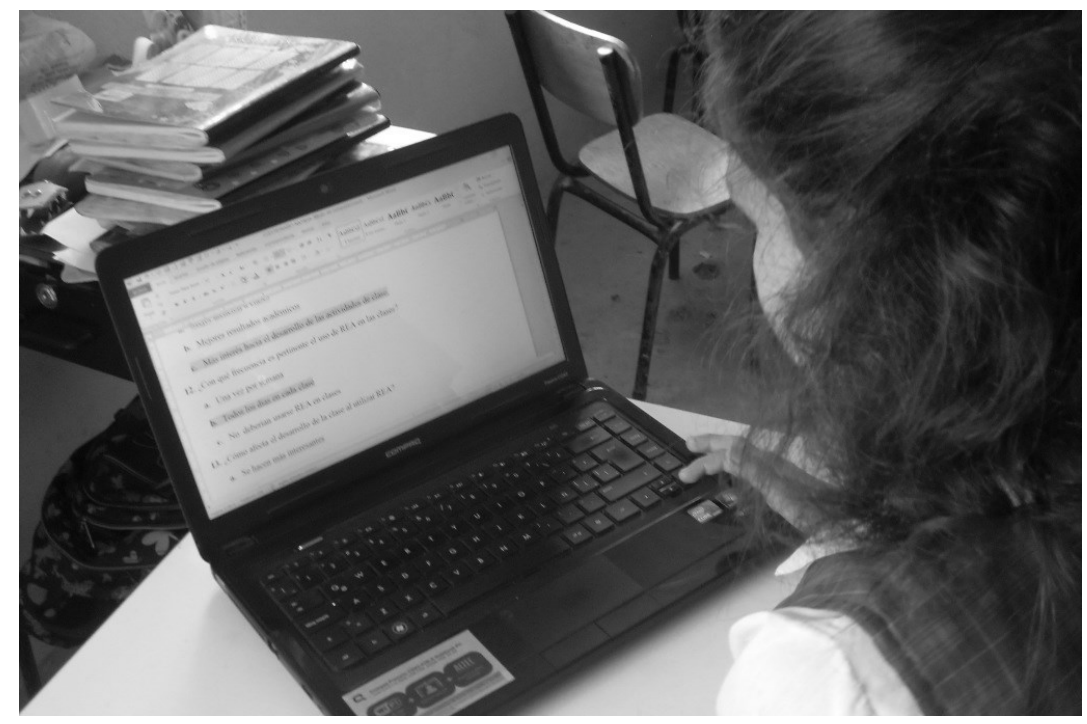

Figura 11. Estudiante resolviendo el cuestionario

4.1.4 Caso C. El tercer alumno que participó en la investigación cursaba el tercer grado y contaba con 8 años de edad; con una actitud que demostraba interés por realizar las actividades pero su rendimiento académico no era el mejor, no se concentraba fácilmente y era de los estudiantes que en el tablero resolvía las operaciones o contestaba correctamente pero cuando respondía una evaluación escrita sus resultados eran negativos. Siempre manifestaba saber cómo hacer las cosas pero sus resultados indicaban lo contrario.

\section{Familiarización}

A partir de la observación de sus actividades al usar REA, registradas en el diario de campo de la investigadora, se evidenció que se trataba de un niño cuya interacción con la 
tecnología había sido limitada pero mayor que la de los otros dos participantes del estudio. Se mostró interesado y atento a las actividades que debía realizar y a medida que iniciaba una de ellas, quería ser el primero en realizarlas, o cuando estaba algún compañero realizando su actividad lo interrumpía y se le adelantaba para presentar el resultado, lo que incomodaba a los demás compañeros quienes le llamaban la atención para que respetara el turno y los dejará resolver solos la actividad.

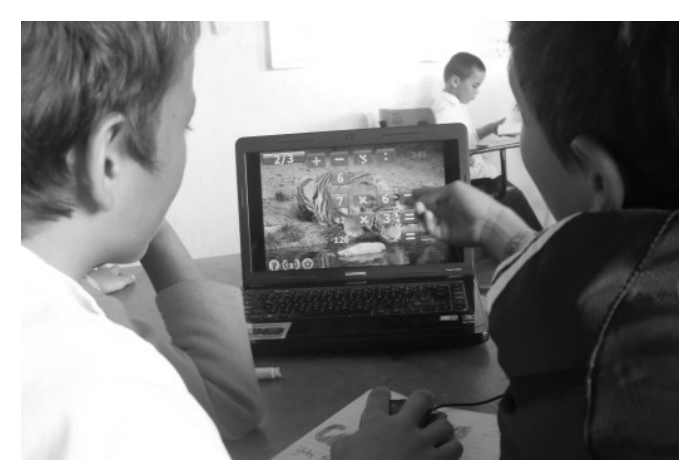

Figura 12. Estudiantes realizando multiplicaciones

\section{Utilización}

Durante las sesiones de actividades realizadas, la actitud del alumno era la de tener el control en todo momento y de realizar las actividades sin darle oportunidad a sus otros compañeros. A pesar de que en varias ocasiones no realizaba correctamente las actividades, su interés hacia ellas no se ponía en duda, aunque cabe mencionar que en algunas ocasiones nada parecía interesarle.

\section{Alfabetización digital}

En una de las sesiones, el alumno le manifestó a sus compañeros que él no quería realizar las actividades en la computadora porque en la casa ya estaba cansado de usarla. $\mathrm{Al}$ 
oír esto la docente le preguntó: “¿Qué actividades realizas en tu casa?”, a lo que el niño le respondió: “'Sólo me la paso jugando!”, “juegos educativos?” preguntó nuevamente la docente. El estudiante guardó silencio y luego de unos segundos su respuesta fue: "no", a lo que la docente le comenta: "cómo no te vas a cansar y a aburrir si no le estas dando el uso adecuado a tu herramienta tecnológica, ¿eres el único afortunado de tus compañeros que cuenta con una computadora en casa y no aprovechas para profundizar las actividades vistas en clase?, ¡vas a ver que la computadora no solo sirve para juegos sin fundamento educativo!”.

La profesora abrió su computadora portátil y comenzó a ejecutar algunos de los REA que había seleccionado y les fue comentando a los estudiantes cómo se puede aprender jugando. Además les decía que recordaran las actividades anteriores que han realizado en las cuales han jugado y aprendido a multiplicar. Ellos atentos la miraban y escuchaban. Seguida de esa explicación, el estudiante no volvió a mostrarse insatisfecho.

\section{Utilización}

A pesar de manifestar que el alumno utilizaba la computadora en su casa, la profesora debió explicarle en varias ocasiones cómo debía responder el cuestionario virtual. No recordaba que teclas debía usar, ni otros comandos que ya se le habían orientado. A diferencia de sus otros dos compañeros, él fue el más inseguro con esta actividad. Aunque se dejaba solo para que se familiarizara con la herramienta se demoró en tomar confianza y agilidad.

\section{Aceptación de los REA en el desarrollo de las actividades}


Durante el desarrollo del cuestionario, el alumno intentaba preguntar a la docente qué respuesta debía colocar. Pero estas actitudes manifestadas por el estudiante no se presentaban en la práctica ya que durante las observaciones se pudo evidenciar que el alumno realizaba las actividades sin problemas en donde, a diferencia de sus compañeros, él tuvo mayor facilidad con las tablas de multiplicar. Se pudo detectar que su nivel de apropiación llegó al que se denomina como integración.

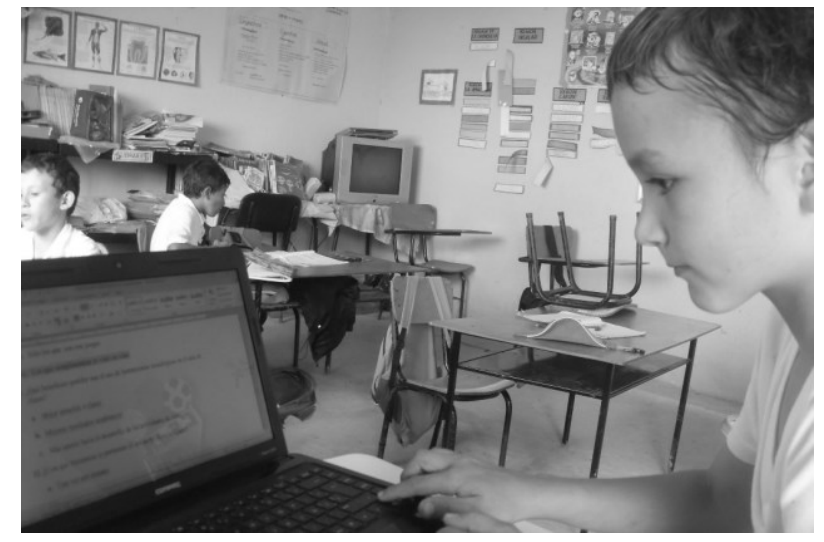

Figura 13. Estudiante resolviendo el cuestionario

\section{Impacto en los procesos de enseñanza-aprendizaje}

Los casos descritos anteriormente, evidencian a tres estudiantes cuyas características personales de aprendizaje son diferentes. Fue enriquecedor ver como los estudiantes realizaban las actividades con REA de una manera agradable, con interés y deseo que explorar cada vez más. Sus expectativas eran altas con respecto a las actividades que se harían en cada sesión, lo cual lleva a concluir que un recurso bien utilizado y sobre todo en contextos donde su familiarización no es amplia, genera resultados positivos en cuanto a los aspectos escolares y personales.

\subsection{Análisis e interpretación de resultados}




\subsubsection{Nivel de apropiación tecnológica.}

\section{Familiarización}

Cada vez es más común que los estudiantes tengan un mayor interés por nuevas herramientas tecnológicas que se incluyan en el aula como complemento de las actividades. En los resultados descritos en el caso A del presente estudio se encontró que tras la aplicación de instrumentos y observación directa, el estudiante mostraba interés y curiosidad cuando trabajaba con herramientas tecnológicas, particularmente con los REA. De acuerdo con Hooper y Rieber (1995) la familiarización debe ser el primer nivel por el que atraviese un usuario con respecto a la apropiación tecnológica. De acuerdo con ello, se afirma que el proceso de familiarización se presenta en los estudiantes cuando existe una interacción con un recurso antes desconocido y que eventualmente se van conociendo sus particularidades.

\section{Utilización}

El uso de un recurso dentro del aula de clases debe tener una finalidad clara y pertinente con el contexto y las necesidades que se presenten. En el estudio se encontró que era importante utilizar recursos que ayudaran a reforzar los conocimientos acerca de operaciones matemáticas, específicamente las de multiplicación ya que los alumnos presentaron dificultades en su aprendizaje. En concordancia con Abelleira (2011) existen espacios, tiempos, oportunidades y posibilidades gratuitas para que el profesor se informe, forme, actualice y se provea de recursos para innovar en el aula, es así como se mejora la práctica educativa, al igual que dejar de pensar que innovación es contar con las herramientas o el acceso a internet (Bridges, 2004). Con base en lo anterior, se entiende que 
el buen uso que se le dé a las tecnologías dentro del aula de clases depende en gran parte del docente que esté orientando la actividad y debe ser él, el primero en conocer la función y el objetivo significativo que va a alcanzar con su uso.

\section{Integración, reorientación y evolución}

Los docentes consideran que integrar nuevas tecnologías dentro del aula se convierte en un reto debido al proceso que conlleva desde integrar los recursos como herramientas de enseñanza hasta percibir los beneficios en el proceso de construcción de conocimiento de los alumnos. En los tres casos de estudio, A, B y C, los estudiantes integraron la tecnología a los contenidos analizados en clase y de igual forma, se evidenció a través de la observación, el cuestionario y los trabajos realizados por los alumnos el deseo por integrar las TIC en las demás áreas. Esta aspiración la compartían junto con la docente y es ahí donde se avanza a la fase de evolución en la apropiación tecnológica, en donde la integración se dio desde el instante en que se planeó el objetivo de uso de estos recursos. Es así, como Gunn, Woodgate y O’Grady (2005) describen la introducción de las nuevas tecnologías, a través de pasos como la utilidad, la participación temprana, pruebas piloto, aceptación, introducción, uso y cambio organizacional y desarrollo; y Ramírez (2012) quien menciona la importancia de elegir recursos de fácil aplicación y acorde a las necesidades y/o expectativas. Por ello, el integrar, reorientar y evolucionar las nuevas tecnologías en las actividades académicas permiten un aprendizaje significativo siempre y cuando se planteen objetivos claros y pertinentes de uso. 


\subsubsection{Evaluación de los entornos con REA.}

\section{Tipos de REA utilizados}

El REA más atractivo para los estudiantes es aquel que es dinámico por su contenido multimedia y no los recursos que solamente contienen texto plano. Tras la aplicación de un cuestionario se encontró que los REA más atractivos para los alumnos fueron aquellos con aplicaciones interactivas en la computadora; a través de la observación se percibió en los niños menos inclinación hacia recursos como el video, que aunque es de su agrado, no les permite la manipulación de la herramienta como si lo hace una aplicación en la computadora. Para Glasserman, Mortera y Ramírez (2013) hay diferentes tipos de REA entre los que destacan cursos completos, materiales, módulos, libros, videos, exámenes, software y herramientas, materiales o técnicas empleadas para dar soporte y acceso al conocimiento aunque para Wilson (2008) y Wiley (2007) no todos los recursos pueden transformarse debido a que no son editables o presentan restricciones en cuanto a funcionar con conexión a internet. De esta forma se puede apreciar que no todos los REA son aplicables a cualquier contexto, sino que se debe elegir el más adecuado tomando en cuenta las necesidades e intereses de los estudiantes.

\section{Frecuencia de uso de REA}

Los REA pueden incluirse como herramientas de apoyo en el aula al menos una vez al día para apoyar el contenido que se presenta y vincularlos con otras prácticas educativas. Mediante la aplicación del cuestionario se identificó la atracción que tienen los alumnos por utilizar REA en su proceso de aprendizaje y dos de los alumnos indicaron que prefieren utilizarlos una vez por semana, mientras que un participante indicó que le gustaría utilizarlo 
diariamente. En dialogo con los alumnos indicaron su preferencia por intercalar estas actividades con lecturas y clases al aire libre. Es Cobo (2007) quien menciona la importancia de incorporar nuevas ideas al aula, para construir conocimiento a través de la experimentación con diferentes herramientas tecnológicas. Es así, como los docentes pueden elegir entre la gran variedad de recursos educativos que existen, para aplicarlos en sus actividades académicas sin que se conviertan en un recurso monótono y del cuál los estudiantes terminen perdiéndole el agrado y la expectativa.

\section{Impacto en los procesos de enseñanza aprendizaje}

Incluir nuevos recursos didácticos en el aula permite un mejor ánimo de los alumnos y por consiguiente se genera un ambiente propicio para incentivar el nivel de aprendizaje. Se observó en los participantes que utilizaron REA en el aula un cambio de actitud, de interés y motivación hacia la realización de las actividades donde fue notoria la sensación y el deseo por iniciar la actividad. Se percibió que cuando la docente llevaba su computadora generaba alegría, atención, curiosidad y sobre todo ganas de aprender en los alumnos.

Según Burgos y Ramírez (2011b) la nueva tecnología se presta a la construcción conjunta de significados, el trabajo colectivo en proyectos de interés por los alumnos, el desarrollo solidario de nuevos conocimientos y el uso simultáneo de diferentes medios para lograr objetivos comunes de alto valor comunitario. Por lo tanto, es importante generar cada vez más espacios para que los estudiantes interactúen con recursos didácticos y de esa forma los alumnos estén más motivados para fomentar su aprendizaje. 


\subsubsection{Innovación con REA en ambientes educativos rurales.}

\section{Planeación de las actividades con uso de REA}

Contar con herramientas tecnológicas dentro de un aula de clases en un entorno rural contribuye a cerrar la brecha digital que aún existe en este tipo de ambientes de aprendizaje. En el estudio se encontró que uno de los participantes nunca antes había tenido oportunidad de utilizar una computadora portátil y tras las prácticas de las actividades logró con facilidad realizar las tareas propuestas como se observó en cada una de las sesiones. Los REA se convirtieron en un apoyo para el desarrollo de las clases y ayudaron a distribuir mejor el tiempo de la maestra para el trabajo con cada grupo por tratarse de un aula multigrado, hechos que quedaron evidenciados en el diario del investigador. A propósito de esto, Celaya, Lozano y Ramírez (2010) afirman que los recursos tecnológicos son elementos que apoyan el trabajo docente y Ramírez (2012) hace claridad en cuanto a que los REA reducen el tiempo de preparación de clases, todo depende de encontrar un recurso que esté acorde a las expectativas y que sea de fácil aplicación. Es decir, una correcta identificación y aplicación de este tipo de recursos permite un aprendizaje significativo en los estudiantes y logra motivarlos así como despertar su interés hacia las actividades académicas. En otras palabras, la innovación educativa a través de REA y herramientas tecnológicas son fundamentales para darle un uso adecuado al tiempo de clases en zonas rurales donde en ocasiones los docentes atienden a todos los grados a la vez.

\section{Aceptación de los REA en el desarrollo de las actividades}

La aceptación de los REA en las actividades de clase en ambientes rurales es efectiva, de interés, motivante, genera confianza y deseo de aprender. A través del cuestionario y del 
dialogo, un estudiante manifestó que el uso de REA fue muy interesante porque aprendió el contenido de matemáticas; otro participante mostró agrado por conocer, aprender y utilizar estas herramientas; y otro alumno parecía desinteresado hacia las actividades iniciales pero conforme fue interactuando con los REA, se percibió más interesado en utilizarlos. Así, se identificó a los estudiantes de tercer grado que trabajaron con REA motivados, con confianza y dispuestos a aprender más, en comparación que antes que no se utilizaban recursos como los REA y la computadora. Al respecto, McAndrew (2011) menciona que los docentes pueden adoptar y utilizar los REA de forma que estos ayuden a modificar sus prácticas educativas y lograr mayor productividad del recurso llevándolos a diferentes contextos. Es decir, que el uso de REA en las actividades escolares es benéfico tanto para los estudiantes que han interactuado con la computadora, como para aquellos que sus posibilidades han sido pocas.

\section{Alfabetización digital}

Es necesario considerar aspectos vulnerables de la tecnología, tanto en ambientes urbanos como en ambientes rurales, con respecto a fallas en conectividad en los equipos y desarrollar el criterio para saber cómo buscar recursos en internet. La observación a los participantes cuando utilizaban la computadora y los registros del diario de la investigadora, evidenciaron que era necesario que los docentes aprendieran no solamente cómo desarrollar las actividades del REA, sino que se requerían fortalecer sus conocimientos tecnológicos de manera general. Es así, como Muñoz y Sanhueza (2006) afirman que en la educación rural se debe contar con directrices que permitan introducir y conocer estrategias pedagógicas encaminadas a la calidad, gestión y fortalecimiento de 
habilidades. Es decir que la tecnología no debe ser pensada como infalible y ante ello, los docentes deben tener conocimiento acerca de la situaciones que se les pueden presentar y cómo pueden hacer frente a las mismas.

En conclusión, este capítulo evidenció los hallazgos obtenidos en el estudio donde se utilizaron REA con estudiantes de educación básica primaria rural, los cuales lograron una apropiación tecnológica cuando su interacción con la tecnología había sido limitada. En el siguiente capítulo se hace mención a la discusión, conclusiones y recomendaciones para futuras investigaciones. 


\section{Capítulo 5. Discusión, conclusiones y recomendaciones}

Este capítulo presenta un análisis sobre la importancia de la investigación realizada dentro del ámbito de la educación básica de nivel primaria, en el sector rural; estableciendo cómo se dio respuesta a la pregunta de investigación, el alcance del objetivo y supuestos planteados al inicio del estudio. Asimismo, se presentan algunas sugerencias para futuras investigaciones.

\subsection{Sobre la pregunta de investigación}

En relación con la pregunta de investigación planteada para esta investigación:

¿Cómo se desarrolla la apropiación tecnológica en los alumnos de educación básica primaria rural al trabajar con recursos educativos abiertos? La apropiación tecnológica se desarrolla tomando como base cinco etapas (familiarización, utilización, integración, reorientación y evolución):

a) En la etapa de familiarización la apropiación tecnológica se desarrolla cuando los alumnos conocen por primera vez los recursos tecnológicos tal y como ocurrió con la computadora y los REA en el estudio.

b) La fase de utilización se desarrolla cuando se utiliza la computadora y los REA en actividades cotidianas, donde destacó el cambio en la actitud y motivación de los estudiantes.

c) La fase de integración se desarrolla cuando los alumnos se apoyan en los recursos para realizar actividades dentro de clase tal y como ocurrió cuando respondían a un cuestionario en línea o cuando escribían en el documento de Word. 
d) La fase de reorientación se desarrolla cuando los alumnos entienden que los dispositivos y recursos tecnológicos son herramientas para la construcción de conocimiento. Por lo tanto el REA y la computadora actúan como un medio y no como un fin para lograr el aprendizaje en los alumnos, tal y como ocurrió en el estudio con el contenido matemático.

e) La fase de evolución se desarrolla cuando los alumnos comprenden que los recursos tecnológicos tienen diferentes usos, por ejemplo la computadora y los REA se aplicaron de diferente forma durante el estudio.

Como se puede evidenciar, la pregunta de investigación fue resuelta siguiendo las etapas de apropiación tecnológica de Hooper y Rieber (1995) en donde la docente y estudiantes que participaron en el estudio lograron superar cada etapa a pesar de encontrarse en un contexto rural donde se presentaron dificultades de acceso a herramientas tecnológicas.

\subsection{Sobre el objetivo de investigación}

El objetivo de la presente investigación y que sirvió como base para llevar a cabo el estudio fue: analizar el desarrollo de la apropiación tecnológica en alumnos de tercer grado de educación básica de una primaria rural, con un ambiente de aprendizaje que integró recursos educativos abiertos de contenidos en el área de matemáticas de operaciones básicas (adición, sustracción, multiplicación y división), solución de problemas, lectura y escritura de números; con el fin de contribuir con la innovación en los ambientes de aprendizaje de educación básica en contextos rurales. Cabe destacar que el objetivo del estudio se logró al revisar los hallazgos en cada una de las etapas de apropiación tecnológica en las que se ubicó a los participantes del estudio, así como con las 
evidenciadas a partir del uso de instrumentos como la observación de las actividades significativas de los alumnos, el diario del investigador, un cuestionario y trabajos de los alumnos resultado de la integración de REA relacionados con operaciones matemáticas como la multiplicación.

\subsection{Sobre los supuestos de investigación}

Dentro de la investigación se presentaron dos supuestos. El primero consistió en si era pertinente plantear que los estudiantes de educación primaria de un contexto rural no habían tenido un acercamiento e interacción con la tecnología y cuando esto ocurriera, querrían regresar a métodos de aprendizaje tradicionales.

Con base en los resultados se puede afirmar que el primer supuesto no es aceptado, debido a que una vez los estudiantes interactuaron con la herramienta tecnológica y con los REA, querían seguir utilizándolos. Los alumnos indicaron que se les facilitaba la realización de operaciones matemáticas como la multiplicación al trabajar con esos recursos. Este supuesto permite concluir que, aunque los estudiantes han tenido poca interacción con la tecnología, les parece interesante, novedosa, y de gran ayuda para sus procesos de aprendizaje, no pretenden desprenderse de la interacción entre personas, de actividades tradicionales constructivas como trabajos en equipo, juegos al aire libre, guías de libros, que resulta ser positivo, porque así no se tiene la idea de que para aprender solo se necesita de una herramienta tecnológica.

El segundo de los supuestos consistió en si la aplicación de REA con diseños atractivos, motivadores y afines con el nivel de enseñanza de los estudiantes, lograría en 
ellos mayor interés y desempeño académico en cada una de las áreas en las que se emplearan.

Esta afirmación es válida porque los estudiantes manifestaron con sus actitudes y actividades, que los REA despertaban en ellos mayor interés en la realización de las actividades de clase, en la medida en que se iban familiarizando con el recurso y con las actividades, su rendimiento era mejor.

\subsection{Recomendaciones para futuras investigaciones}

De acuerdo con el análisis de los resultados del presente estudio, surgen una serie de recomendaciones a tener en cuenta para futuras investigaciones. La primera corresponde en vincular a docentes de otras áreas, integrarlos y motivarlos a que diseñen y hagan uso de REA en sus actividades escolares.

De igual manera, es pertinente hacer uso de REA para otras áreas del saber como lengua castellana, inglés y ciencias naturales. Asimismo, antes de utilizar cada REA es conveniente que el estudiante o participante de la investigación ya tenga una aproximación al contenido para aprovechar mejor el recurso.

Por otra parte, es importante que los REA sean seleccionados según las necesidades de los participantes y del contexto en el cual se van a aplicar. Asimismo, se puede realizar un estudio de seguimiento longitudinal de tal forma que se pueda revisar qué ocurre con los participantes de este estudio y su nivel de apropiación tecnológica en el futuro. Otra propuesta consiste en repetir el estudio en otras localidades rurales que permita tener datos para comparar cómo contribuye el uso de REA en los procesos de apropiación tecnológica. 
Se podría considerar un estudio correlacional para tener el nivel de apropiación tecnológica y el uso de REA en el aula en ambientes rurales.

En resumen, en este capítulo se respondió la pregunta de investigación para la cual fueron alcanzadas las etapas de la apropiación tecnológica, se indicó el alcance del objetivo, de los supuestos y se plantearon recomendaciones para futuras investigaciones. 


\section{Referencias}

Abelleira, A. (2011). ¿Competencia digital o manejo de tecnología? En J. Hernández; M. Pennesi; D. Sobrino y A. Vázquez (Coords.), Experiencias educativas en las aulas del siglo XXI: Innovación con TIC (pp. 21-24). Madrid, España: Ariel y Fundación Telefónica. Disponible en: http://www.ciberespiral.org/attachments/225_Experiencias_educativas20.pdf

Adame, S.I., Barriga, J.A. y Navarro, J. (2011). El cuestionario. [Recurso Educativo Abierto]. Disponible en el Instituto Tecnológico y de estudios superiores de Monterrey, en el sitio web: http://catedra.ruv.itesm.mx/handle/987654321/304

Andión, M. (2010). Equidad tecnológica en la educación básica: Criterios y recomendaciones para la apropiación de las TIC en las escuelas públicas. Reencuentro, 59, 24 -32.

Arenas, P. (2013). Plan Estratégico Departamental de Ciencia, Tecnología e Innovación (PEDCTI Santander). Disponible en: http://www.santander.gov.co/index.php/documentos-setic/finish/73-setic/4116documento-pedcti-santander

Blackall, L. (2008). Open educational resources and practices. TESL-EJ, 11(4), 1-19.

Barrett, H. (2003). Field guide to appropriate technology. Estados Unidos: Academic press.

Belleï, C. (2013). Situación educativa de América Latina y el Caribe: hacia la educación de calidad para todos al 2015. Santiago de Chile, Chile: Imbunche Ltda.

Bridges. Org. (2004). Additional reading: Real Access / Real Impact Framework for ICT in development. Disponible en:

http://old.apc.org/english/capacity/policy/mmtk_realaccess_additional_reading.doc

Burgos, J. V. y Ramírez, M. S. (2011a). Movilización de Recursos Educativos Abiertos (REA): Enriqueciendo la práctica educativa. Revista digital La educación, 146, 1 16.

Burgos, J. V. y Ramírez, M. S. (2011b). Transformando Ambientes de Aprendizaje en la Educación Básica con Recursos Educativos Abiertos. Monterrey, México: Lulú.

Burgos, J. V. y Ramírez, M. S. (2013). Academic Knowledge Mobilization to Promote Cultural Change Towards Openness in Education. En R. McGreal; W. Kinuthia y S. Marshall (Eds.), Perspectives on Open and Distance Learning: Open Educational 
Resources: Innovation, Research and Practice (pp. 17-32). Vancouver, Canada:

Commonwealth of Learning and Athabasca University.

Cabero, J. A. (2004). Reflexiones sobre la brecha digital y la educación. En F. Soto y J. Rodríguez (Coords) Tecnología, educación y diversidad: retos y realidades de la inclusión digital (pp. 23 - 42). España: Murcia. Disponible en:

http://tecnologiaedu.us.es/nweb/htm/pdf/brecha.pdf

Celaya, R., Lozano, F. y Ramírez M. (2010). Apropiación tecnológica en profesores que incorporan Recursos Educativos Abiertos en educación Media Superior. Revista Mexicana de Investigación Educativa, 45(15), 487-513.

Clements, K.I. y Pawlowski, J.M. (2011). User-oriented quality for OER: understanding teachers' views on re-use, quality, and trust. Blackwell Publishing, 28, 4-14. Doi: 10.1111/j.1365-2729.2011.00450.x

Cobo, R. C. (2007, diciembre). Aprendizaje adaptable y apropiación tecnológica: reflexiones prospectivas. Documento presentado en el Tercer encuentro de Auto estudios de las Universidades Públicas Mexicanas. Facultad Latinoamericana de Ciencias Sociales, México

Cobo, C. y Moravec, J.W. (2011). Aprendizaje Invisible. Hacia una nueva ecología de la educación. Barcelona, España: Universitat de Barcelona.

Colás, P. y Jiménez, R. (2008). Evaluación del impacto de la formación (online) en TIC en el profesorado. Una perspectiva sociocultural. Revista de Educación, 346, 187-215.

Colás, P., Rodríguez, M. y Jiménez, R. (2005). Evaluación de e-learning. Indicadores de calidad desde el enfoque sociocultural. Teoría de la educación y Cultura en la Sociedad de la Información (en línea), 6(2). Disponible en: http://www.usal.es/ teoriaeducacion/rev_numero_06_2/n6_02_art_colas_rodriguez j imenez.htm

Contreras, R.S. (2010). Recursos Educativos Abiertos: Una iniciativa con barreras aún por superar. Apertura, 10(13), 86 - 97.

CPE. (2008). Computadores para Educar: Un camino hacia el conocimiento. Presidencia de la República de Colombia. Consultado en: http://www.computadoresparaeducar.gov.co/inicio/

Creswell, J.W. (1994). Research Design. Qualitative \& Quantitative Approaches. Thousand Oaks. California, Estados Unidos: Sage 
Díaz, M. (2008). Reseña de diez nuevas competencias para enseñar de Philippe Perrenoud. Revista Tiempo de Educar, 9(17), 153-159.

Echeverría, J. (2008). Apropiación Social de las tecnologías de la información y la comunicación. Revista Iberoamericana de Ciencia Tecnología y Sociedad, 10(4), 171 $-182$.

García, F. (2004). El cuestionario: Recomendaciones metodológicas para el diseño de un cuestionario. Córdova, México: Limusa.

García, A., Glasserman, L. D., Lascares, Y. y Perales, M. (2010). Beneficios para el alumno derivado de la adopción de Recursos Educativos Abiertos (REAs) en la práctica educativa. En M. S. Ramírez y J. V. Burgos (Coords.), Recursos educativos abiertos en ambientes enriquecidos con tecnología: Innovación en la práctica educativa (pp.527-542). México: Lulú

Glasserman, L. D., Mortera, F. J. y Ramírez, M. S (2013). Caracterizando recursos educativos abiertos (REA) y objetos de aprendizaje (OA) que fomentan un aprendizaje activo en los alumnos de primaria. En F. J. Mortera y M. S. Ramírez (Eds.), Conexión de repositorios educativos digitales: Educonector.info (pp. 26-34). México: Lulú.

Gunn, C., Woodgate, S y O'Grady, W. (2005). Repurposing learning objects: a sustainable alternative. (ERIC Document Reproduction Service No. EJ820159). Disponible en: http://files.eric.ed.gov/fulltext/EJ820159.pdf

Hepp, P., Hinostroza, E., Laval, E. y Rehbein, L. (2004). Technology in Schools:

Education, ICT and the Knowledge Society. World Bank, Distance \& Open Learning and ICT in Education Thematic Group, Human Development Network, Education. Ceppe, 1-86.

Heredia, Y., Escamilla, J.G. y Gómez, M.G. (2006). Centros comunitarios de Aprendizaje: Modelo, estrategia y programas educativos para apoyar la inclusión social y el desarrollo de poblaciones indígenas y rurales. Reporte de investigación. Monterrey, México.

Hernández, J.P. y Villarreal, J. (2013). Informe de Indicadores Sectoriales que Permiten Medir el Avance de Colombia en la Sociedad de la Información. (Informe № 5000-459). Comisión de Regulación de Comunicaciones. Colombia.

Hooper, S. y Rieber, L. P. (1995). Teaching with technology. En A. C. Ornstein (Ed.), Teaching: Theory into practice, (pp. 154-170). Needham Heights, Massachusetts, Estados Unidos: Allyn and Bacon. 
INTEGRA. (2006). Herramientas para la gestión de proyectos educativos con TIC. Buenos Aires, Argentina: IIPE - UNESCO.

Laffey, J. (2004). Appropriation, Mastery and Resistance to Technology in Early Childhood Preservice Teacher Education. Journal of Research on Technology in Education, 36(4), 361-382. Recuperado de Academic Research Library database. (Document ID: 691495821).

McAndrew, P. (2011). Inspiring creativity in organizations, teachers and learners through open educational resources. Disponible en: http://www.eurodl.org/materials/special/2011/McAndrew.pdf

Malpica, F. (2013). 8 ideas clave: calidad de la práctica educativa. Barcelona, España: Graó.

Martínez, T., Mendías, L. y Mendoza, L.A. (2010). El uso y aprovechamiento de los REA en grupos de quinto grado de primaria, específicamente en la lectura como parte de la asignatura de español. En M. S. Ramírez y J. V. Burgos (Coords.), Recursos educativos abiertos en ambientes enriquecidos con tecnología: Innovación en la práctica educativa (pp.325-343). México: Lulú.

Merriam, S. (2009). Qualitative Research: A Guide to Design and Implementation. USA: Jossey-Bass.

Midoro, (2013). Guidelines on adaptation of the UNESCO ICT competency framework for teachers. UNESCO Institute for Information Technologies in Education. Disponible en: http://iite.unesco.org/pics/publications/en/files/3214726.pdf

Montes, J. A. y Ochoa A., S. (2006). Apropiación de las tecnologías de la información y comunicación en cursos universitarios. Acta Colombiana de psicología, 9(2), 87-100.

Mortera, F. J. (2011).Uso de Recursos Educativos Abiertos para mejorar las prácticas docentes y habilidades digitales: Metodología de búsqueda y adopción de REA. Investigación. RIEEGE. Disponible en: rieege.tecvirtual.mx/index.php/rieege/article/download/4/4

Mortera, F. J. y Burgos, V. (2010, mayo). Innovative Applications Using New Technology: The Case of the Knowledge Hub Search Engine and Open Educational Resources Building Communities of Practice. Documento presentado en la Education and Research Technology (ERT), California, Estados Unidos.

Mueller, J. (2009). Computer Integration in Elementary and Secondary Schools: Variables Influencing Educators. (Disertación doctoral, Universidad Wilfrid Laurier). 
Muñoz, M. A. y Sanhueza, J. A. (2006). Características de la integración curricular de la informática educativa en el currículo del aula multigrado. Revista Iberoamericana de Educación. 1-13.

OCDE, 2008. El conocimiento libre y los Recursos Educativos Abiertos. España: Centro de Nuevas Iniciativas. Consultado en: http://www.oecd.org/spain/42281358.pdf

Overdijk, M. y Diggelen, V. D. (2006, octubre). Technology appropriation in face-to-face collaborative learning. Documento presentado en la First European Conference on Technology Enhanced Learning, Creta, Grecia.

Ramírez, M.S. (2013a). Investigación con estudio de casos. [video]. Disponible en el Instituto Tecnológico y de Estudios Superiores de Monterrey, en el sitio web: http://apps05.ruv.itesm.mx/portal/uvtv/video/video.jsp?folio $=5014$

Ramírez, M.S. (2013b). Triangulación instrumentos y análisis de datos. [video]. Disponible en el Instituto Tecnológico y de Estudios Superiores de Monterrey, en el sitio web: http://apps05.ruv.itesm.mx/portal/uvtv/video/video.jsp?folio=4626

Ramírez, M.S. (2012). Modelos y estrategias de enseñanza para ambientes innovadores. Monterrey, México: Editorial Digital del Tecnológico de Monterrey.

Ramírez, M.S. (2007). Documento de apoyo para el análisis de la praxis: ideas de observación e instrumentos. Documento 35 para tesistas. Disponible con la autora en solramirez@itesm.mx

Rivera, R., López, A. y Ramírez, M.S. (2011). Estrategias de comunicación para el descubrimiento y uso de Recursos Educativos Abiertos. REICE, 9(4), 141 - 157. Disponible en: http://www.redalyc.org/articulo.oa?id=55122156010

Saldaña, B. (2009). Portal de Educación Zona alumnos Primaria. [Recurso educativo abierto]. Disponible en la Junta de Castilla y León, en el sitio web:

http://www.educa.jcyl.es/educacyl/cm/zonaalumnos/tkContent?pgseed=1251958903555\&i $\mathrm{dContent}=20741 \&$ locale $=$ es ES\&textOnly $=$ false

Sánchez, M. C. (2008). Integrando las tecnologías de la información y comunicaciones al proceso de enseñanza-aprendizaje. Reencuentro, 51, 98-110.

Secretaría de Estado de Educación, Formación Profesional y Universidades (2012). La situación actual de los Recursos Educativos Abiertos a nivel mundial. Recuperado de: http://recursostic.educacion.es/blogs/europa/index.php/2012/09/21/la-situacionactual-de-los-recursos-educativos-abiertos-a-nivel-mundial-2 
SeTIC (2012). Creación de la Secretaria Departamental TIC. [video]. Disponible en la Gobernación de Santander, en el sitio web: http://www.santander.gov.co/videossetic/youtubegallery?galleryid $=5 \&$ videoid $=$ IJ_WllAvEHM

Sinisterra, M. M. (2008). Apropiación tecnológica en la educación superior. Aportes a la sociedad del conocimiento. Entramado, 4(2), 102-114.

Spradley, J. P. y Baker, K. (1980). Participant observation. Nueva York, Estados Unidos: Rinehart and Winston.

Stake, R. (2007). Investigación con estudios de casos (4ta. ed.). Madrid, España: Morata

Sunkel, G., Trucco, D. y Möller, S. (2011). Aprender y enseñar con las tecnologías de la información y las comunicaciones en América Latina: potenciales beneficios. CEPAL-Serie Políticas sociales, 169, 1- 67.

Toboso, M.M. (2013). Entre el uso y el no uso de la tecnología: Un enfoque discursivo de la apropiación tecnológica. Revista Sociológica de Pensamiento Crítico, 7(2), 201 214. Disponible en: http://www.intersticios.es/article/view/11662/8243

UNESCO IITE. (2014). Institute for Information Technologies in Education. Consultado en: http://iite.unesco.org/

UNESCO (2002, Julio). Forum on the impact of open courseware for higher education in developing countries: final report. Ponencia presentada en el foro de la UNESCO, Paris, Francia.

UNESCO, (2011). Guidelines for Open Educational Resources (OER) in Higher Education. Consultado en http://unesdoc.unesco.org/images/0021/002136/213605e.pdf

Wiley, D. (2007). On the Sustainability of Open Educational Resource Initiatives in Higher Education. Paper commissioned by the OECD's Centre for Educational Research and Innovation (CERI) for the project on Open Educational Resources, 1-21. Disponible en: http://www.oecd.org/edu/ceri/38645447.pdf

Wilson, T. (2008). New Ways of Mediating Learning: Investigating the implications of adopting open educational resources for tertiary education at an institution in the United Kingdom as compared to one in South Africa. International Review of Research in Open and Distance Learning, 9(1), 1-19.

Yin, R. K. (2003). Case Study Research. Estados Unidos: Sage Publications. 
Yin, R. K. (2006). Case Study Methods. En J.L. Green, G. Camilli, P. B. Elmore (Eds.), Handbook of Complementary Methods in Education Research (pp. 111-122). Estados Unidos: Routledge. Recuperado de: http://www.cosmoscorp.com/Docs/AERAdraft.pdf

Yin, R. K. (2009). Case Study Research (4⿳a ed.). California, Estados Unidos: Sage.

Yuni, J. A. y Urbano, C. A. (2006). Técnicas para investigar y formular proyectos de investigación 2. Córdoba, Argentina: Brujas.

Zea, C. M. (2007). Indicadores TIC para la educación en Colombia. Ministerio de Educación Nacional. Colombia Aprende.

Zermeño, A. I., Rocha, M. A., Aguirre, E. L., Muñoz, F. J., Rocha, M. A. (2007). Una experiencia de intervención comunitaria para el empoderamiento social a través de la apropiación de las tecnologías de información y comunicación. En González, R. y Barrón, M. (Coords.), Experiencias de desarrollo rural. Dos visiones de vinculación universitaria: Colima y Iowa, (pp. 233). Iowa, Estados Unidos: Iowa State University. 


\section{Apéndices}

\section{Apéndice A. Cuadro de triple entrada}

\section{Tema de investigación}

Desarrollo de la apropiación tecnológica con recursos educativos abiertos para el aprendizaje de educación básica primaria rural.

\section{Pregunta de investigación}

¿Cómo se desarrolla la apropiación tecnológica en los alumnos de educación básica primaria rural al trabajar con Recursos Educativos Abiertos?

\section{Objetivos de recolección de datos}

El objetivo del estudio fue analizar el desarrollo de la apropiación tecnológica en alumnos de tercer grado de educación básica de una primaria rural, con un ambiente de aprendizaje que integró recursos educativos abiertos de contenidos en el área de matemáticas de operaciones básicas (adición, sustracción, multiplicación y división), solución de problemas, lectura y escritura de números; con el fin de contribuir con la innovación en los ambientes de aprendizaje de educación básica en contextos rurales.

\section{Supuestos de Investigación}

Es pertinente plantear que si los estudiantes de básica primaria de un contexto rural no han tenido un acercamiento e interacción con la tecnología y cuando esto ocurra, querrán regresar a métodos de aprendizaje tradicionales.

La aplicación de REA con características atractivas, motivadoras y afines con el nivel de enseñanza de los estudiantes, logra en ellos mayor interés y desempeño académico en cada una de las áreas en las que se emplean. 


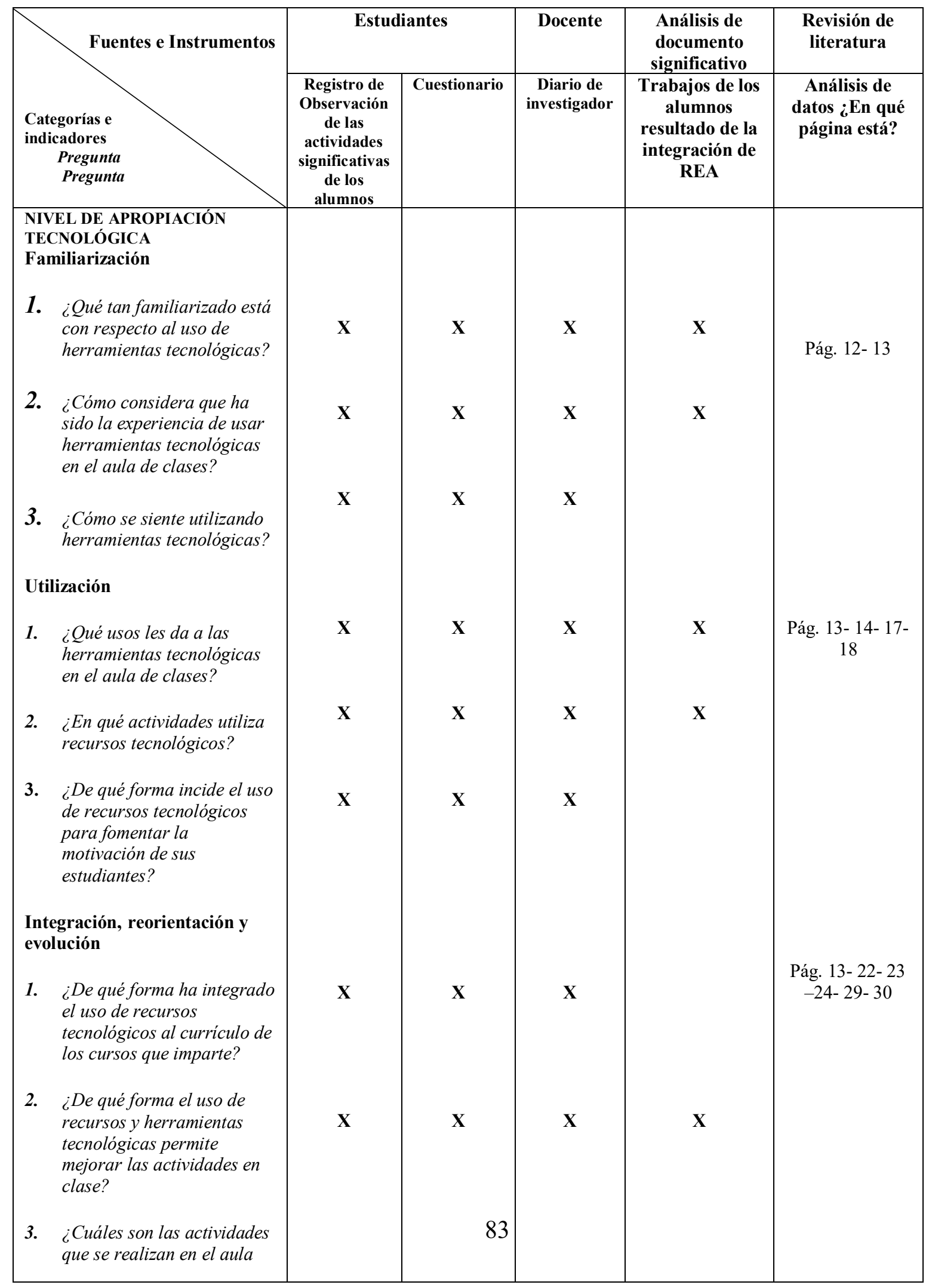




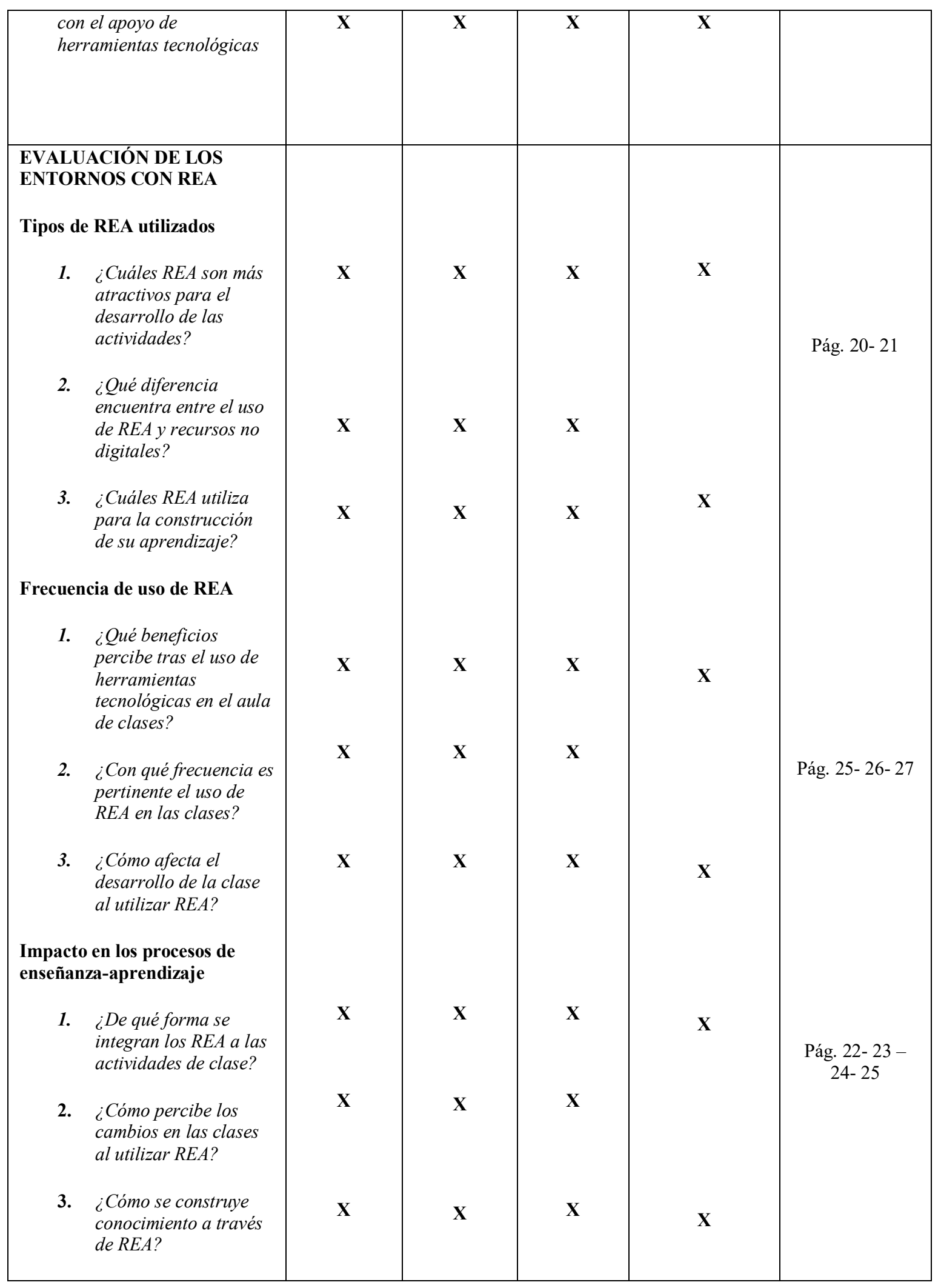




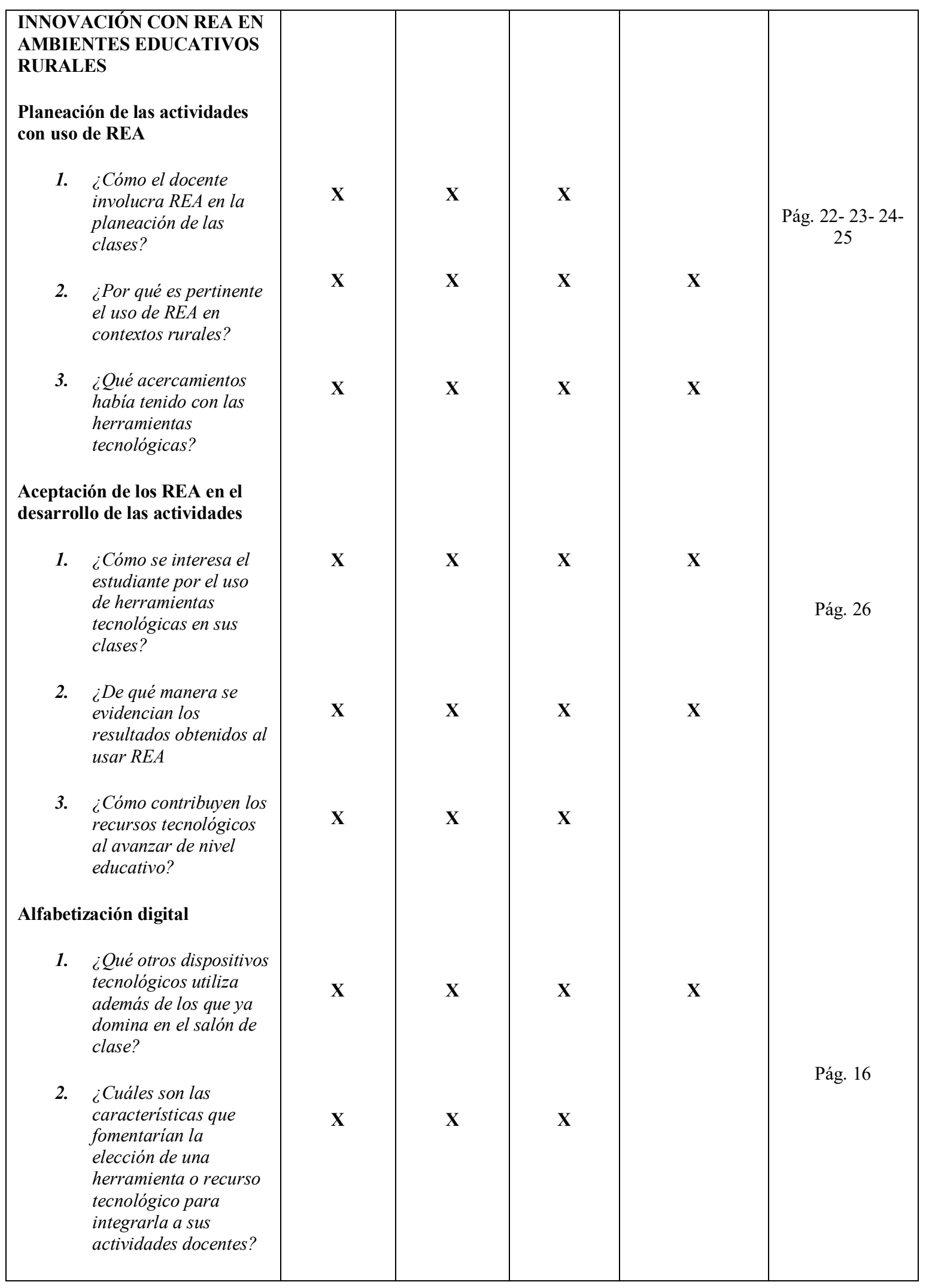




\begin{tabular}{|l|l|l|l|l|l|}
\hline 3. ¿ómo se percibe a sí & & & & \\
mismo con respecto a & $\mathbf{X}$ & $\mathbf{X}$ & $\mathbf{X}$ & & \\
su progreso en la & & & \\
familiarización, uso e & & & & \\
integración de \\
recursos y \\
herramientas \\
tecnológicas en el \\
aula?
\end{tabular}




\section{Apéndice B. Registro de Observación de las actividades significativas de los alumnos}

La información se obtiene a través de registro escrito y registro audiovisual. El registro escrito se realiza a partir del siguiente formato y los registros audiovisuales, se llevan a cabo mediante grabaciones de video y fotografias. Estas últimas servirán para complementar el registro escrito.

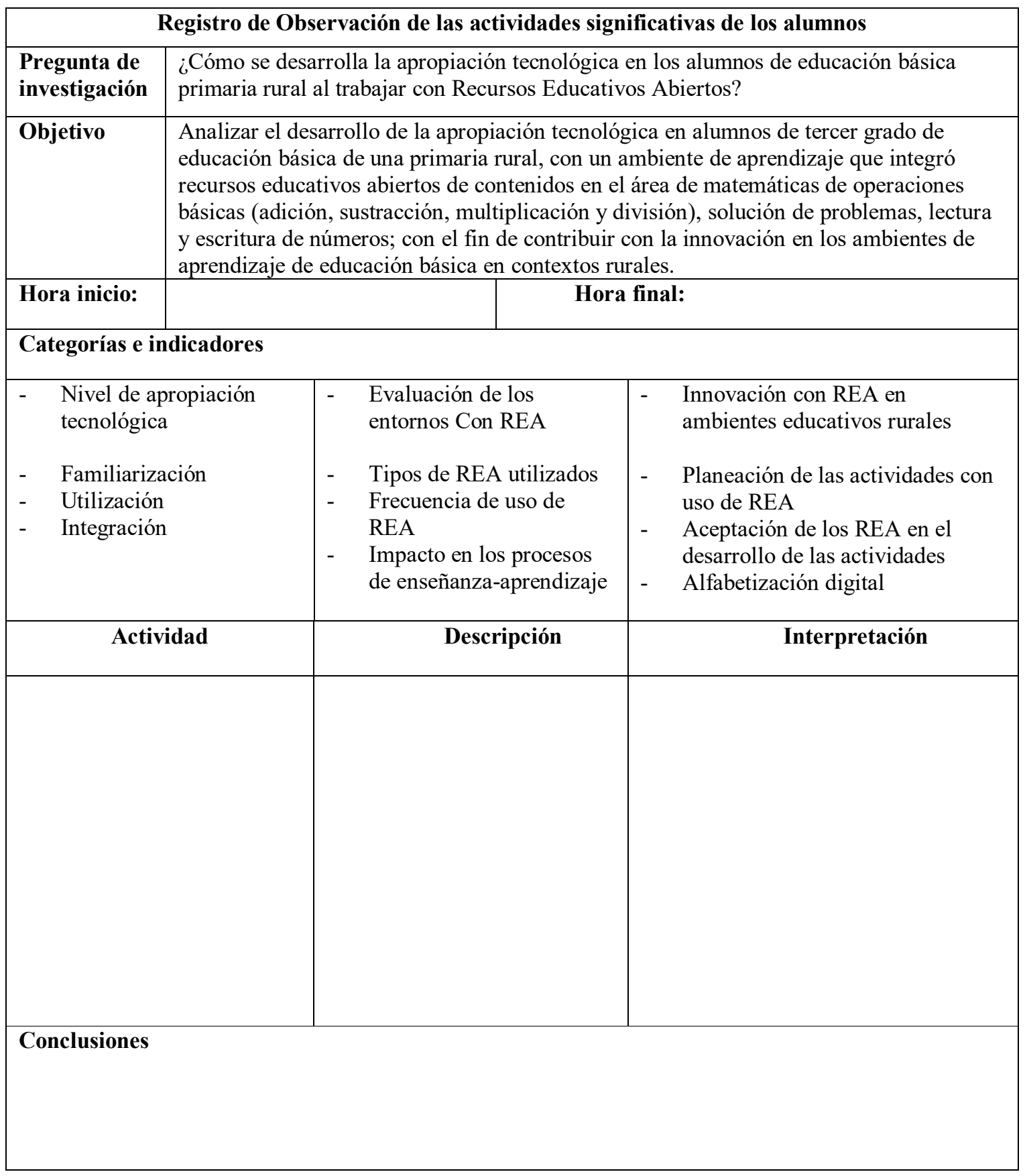




\section{Apéndice C: Diario del investigador}

\section{Nombre:}

Lugar:

Fecha:

Pregunta de investigación: ¿Cómo se desarrolla la apropiación tecnológica en los alumnos de educación básica primaria rural al trabajar con Recursos Educativos Abiertos?

Objetivo: Analizar el desarrollo de la apropiación tecnológica en alumnos de tercer grado de educación básica de una primaria rural, con un ambiente de aprendizaje que integró recursos educativos abiertos de contenidos en el área de matemáticas de operaciones básicas (adición, sustracción, multiplicación y división), solución de problemas, lectura y escritura de números; con el fin de contribuir con la innovación en los ambientes de aprendizaje de educación básica en contextos rurales.

\begin{tabular}{|c|c|c|}
\hline \multicolumn{3}{|c|}{ Observaciones } \\
\hline \multicolumn{3}{|l|}{ Categorías: } \\
\hline \multicolumn{3}{|c|}{ - $\quad$ Nivel de apropiación tecnológica } \\
\hline \multicolumn{3}{|c|}{ Evaluación de los entornos Con REA } \\
\hline \multicolumn{2}{|c|}{ Innovación con REA en ambientes educativos rurales } & \\
\hline Indicadores & Descripción & Interpretación \\
\hline \multicolumn{3}{|l|}{ Familiarización } \\
\hline \multicolumn{3}{|l|}{ Utilización } \\
\hline \multicolumn{3}{|l|}{ Integración } \\
\hline \multicolumn{3}{|l|}{ Tipos de REA utilizados } \\
\hline \multicolumn{3}{|l|}{ Frecuencia de uso de REA } \\
\hline \multicolumn{3}{|l|}{$\begin{array}{l}\text { Impacto en los procesos de } \\
\text { enseñanza-aprendizaje }\end{array}$} \\
\hline \multicolumn{3}{|l|}{$\begin{array}{l}\text { Planeación de las actividades } \\
\text { con uso de REA }\end{array}$} \\
\hline \multicolumn{3}{|l|}{$\begin{array}{l}\text { Aceptación de los REA en el } \\
\text { desarrollo de las actividades }\end{array}$} \\
\hline Alfabetización digital & & \\
\hline
\end{tabular}




\section{Apéndice D: Protocolo de Cuestionario}

- Seleccionar los encuestados

- Definir una cita con los encuestados en un lugar cómodo y sin interrupciones.

- Explicar que las cuestionarios serán video grabados

- Exponer el propósito del cuestionario

- Generar empatía y confianza con los encuestados

Nombre:

Edad: años

Fecha:

Lee detenidamente las preguntas y luego responde con la mayor sinceridad.

1. ¿Qué tan familiarizado está con respecto al uso de herramientas tecnológicas?

a. mucho

b. poco

c. nada

2. ¿Cómo considera que ha sido la experiencia de usar herramientas tecnológicas en el aula de clases?

a. Divertida

b. De aprendizaje

c. Aburrida

3. ¿Cómo se siente utilizando herramientas tecnológicas?

a. Más seguro de lo que voy a hacer

b. Motivado para realizar la actividad

c. Incómodo, no me gustan

4. ¿Qué usos les da a las herramientas tecnológicas en el aula de clases? 

a. De juego
b. De profundización de contenidos
c. De uso libre

5. ¿En qué actividades utiliza recursos tecnológicos?

a. Observar y comprender

b. Leer y escuchar

c. De investigación

6. ¿De qué forma el uso de recursos y herramientas tecnológicas permite mejorar las actividades en clase?

a. Las hace más dinámicas y atractivas

b. Se comprenden mejor los contenidos

c. Mejora el interés por aprender

7. ¿Cuáles son las actividades que se realizan en el aula con el apoyo de herramientas tecnológicas?

a. De apoyo a los temas vistos

b. De evaluación

c. De juego

d. Todas las anteriores

8. ¿Cuáles REA son más atractivos para el desarrollo de las actividades?

a. Videos

b. Libros electrónicos

c. Aplicaciones interactivas en el computador

9. ¿Qué diferencia encuentra entre el uso de REA y recursos no digitales?

a. Los REA son más dinámicos

b. Se aprende más fácil usando herramientas digitales 
c. Los recursos no digitales como cartillas o exposiciones son más fáciles de trabajar.

10. ¿Cuáles REA utiliza para la construcción de su aprendizaje?

a. Los que me facilita la docente

b. Sólo los que son con juegos

c. Los que complementan lo visto en clase

11. ¿Qué beneficios percibe tras el uso de herramientas tecnológicas en el aula de clases?

a. Mejor atención a clases

b. Mejores resultados académicos

c. Más interés hacia el desarrollo de las actividades de clase.

12. ¿Con qué frecuencia es pertinente el uso de REA en las clases?

a. Una vez por semana

b. Todos los días en cada clase

c. No deberían usarse REA en clases

13. ¿Cómo afecta el desarrollo de la clase al utilizar REA?

a. Se hacen más interesantes

b. Permite interactuar con nuevos recursos

c. Ayuda a motivarnos por aprender

14. ¿Cómo percibe los cambios en las clases al utilizar REA?

a. Adecuados

b. Necesarios

c. Poco importantes

15. ¿Por qué es pertinente el uso de REA en contextos rurales?

a. Porque permite conocer nuevas formas de aprendizaje 
b. Porque nos da la oportunidad de interactuar con aparatos tecnológicos

c. No es necesario usar REA en el ámbito rural

16. ¿Qué acercamientos había tenido con las herramientas tecnológicas?

a. mucho

b. poco

c. nada

17. ¿Qué otros dispositivos tecnológicos utiliza además de los que ya domina en el salón de clase?

a. Teléfono celular

b. IPod, Tablet o mp3

c. Televisor y/o computador 


\section{Apéndice E. Solicitud de autorización para realizar la investigación}

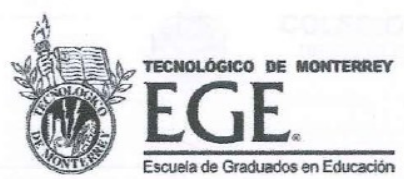

Girón, Santander, Colombia a 19 de marzo de 2014.

Lic. Ramón Antonio Carvajal Chacón

Rector

Colegio San José de Motoso

E. S.M.

Por este medio le solicito autorización para realizar una investigación como parte de mi tesis de maestría, que tiene por objetivo analizar cómo se desarrolla la apropiación tecnológica en los alumnos de educación básica primaria rural, al trabajar con Recursos Educativos Abiertos como herramientas de apoyo para el aprendizaje, con el fin de contribuir con la innovación en dichos ambientes de aprendizaje. Las actividades a realizar serán observar y entrevistar a una muestra de estudiantes de la institución educativa donde laboro y que usted dirige.

Soy alumna de posgrado del Tecnológico de Monterrey y este acercamiento con la realidad sería muy sustantivo para mí proceso de aprendizaje. Tenga por seguro que se salvaguardará toda información que sea confidencial y solamente se utilizará para fines académicos.

Sin otro particular aprovecho la ocasión para hacerle llegar un afectuoso saludo, de antemano agradezco el tiempo dedicado a la presente.

Atte
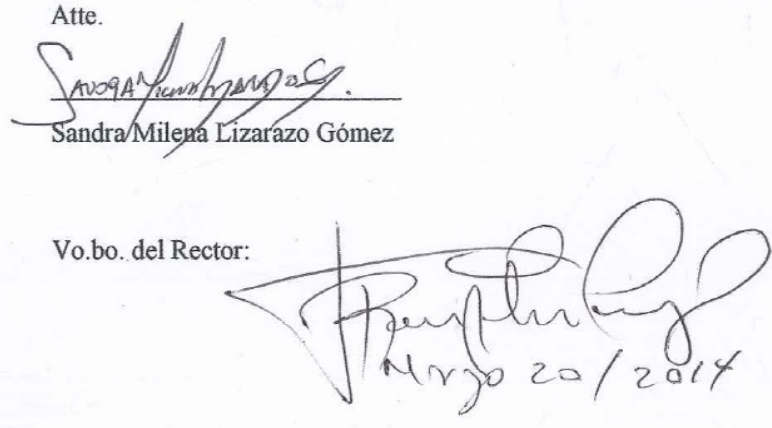


\section{Apéndice F: Autorización para realizar el proyecto de grado}

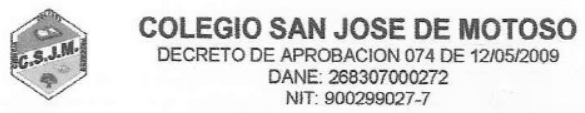

Girón, Santander, Colombia a 19 de marzo de 2014

Asunto: Autorización para realizar proyecto de investigación.

Estimada Sandra Milena Lizarazo Gómez, me permito informarle que cuenta con la

autorización para desarrollar la investigación académica en la sede C de nuestra institución,

de acuerdo con lo presentado en su carta de intención.

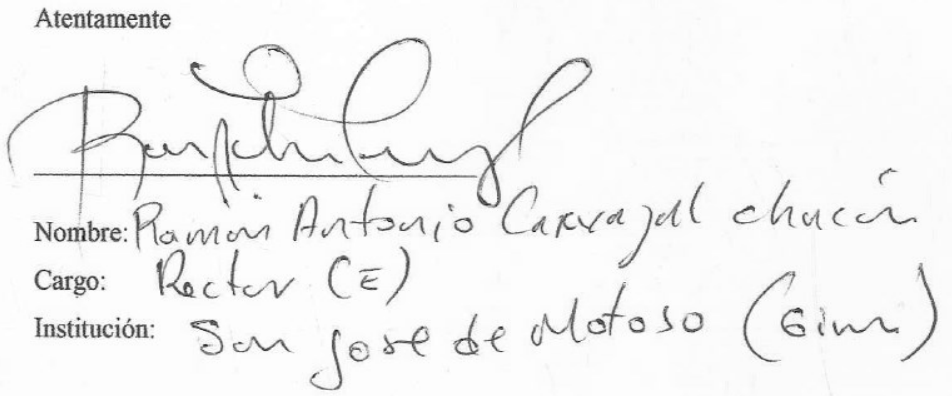




\section{Apéndice G: Fotografías de los estudiantes}

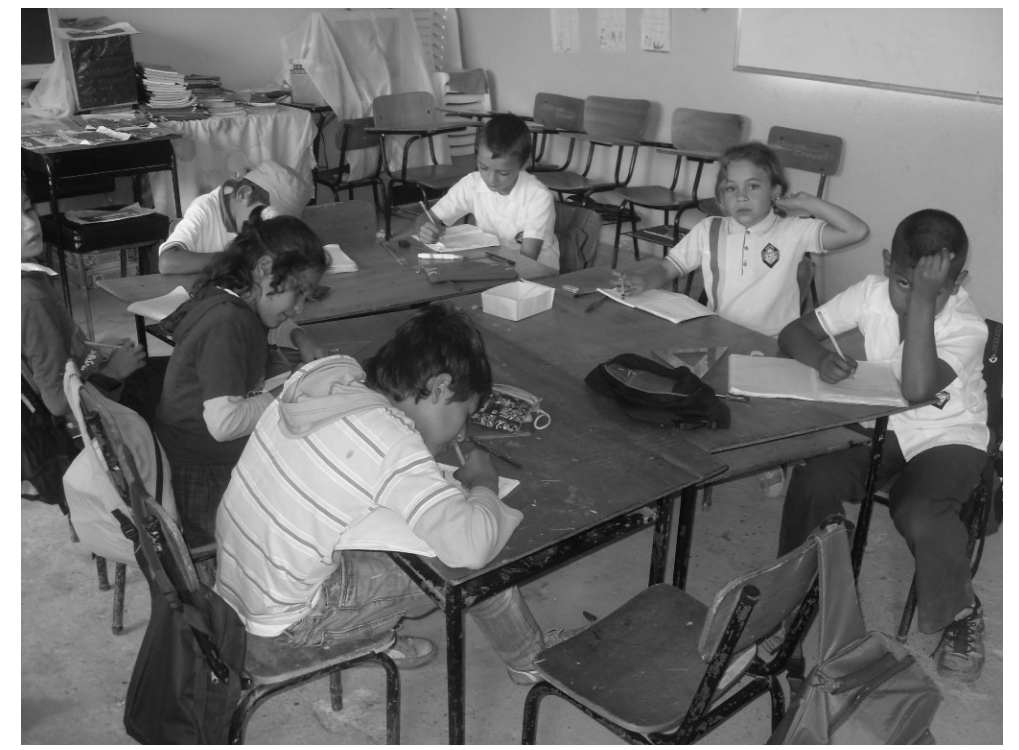

Figura 14. Fotografías del aula de clases

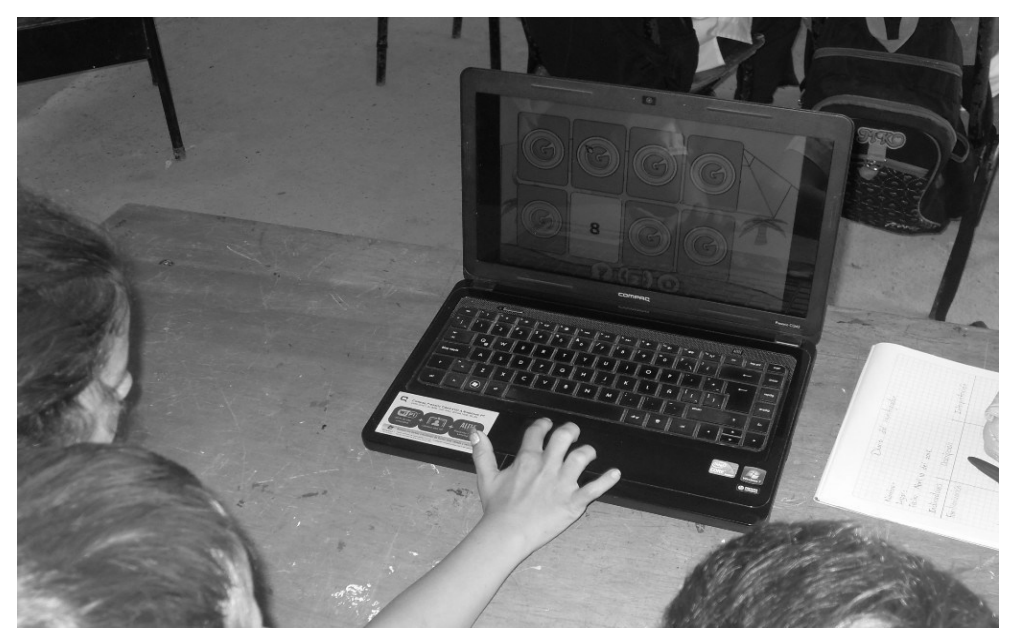

Figura 15. Estudiantes usando REA 


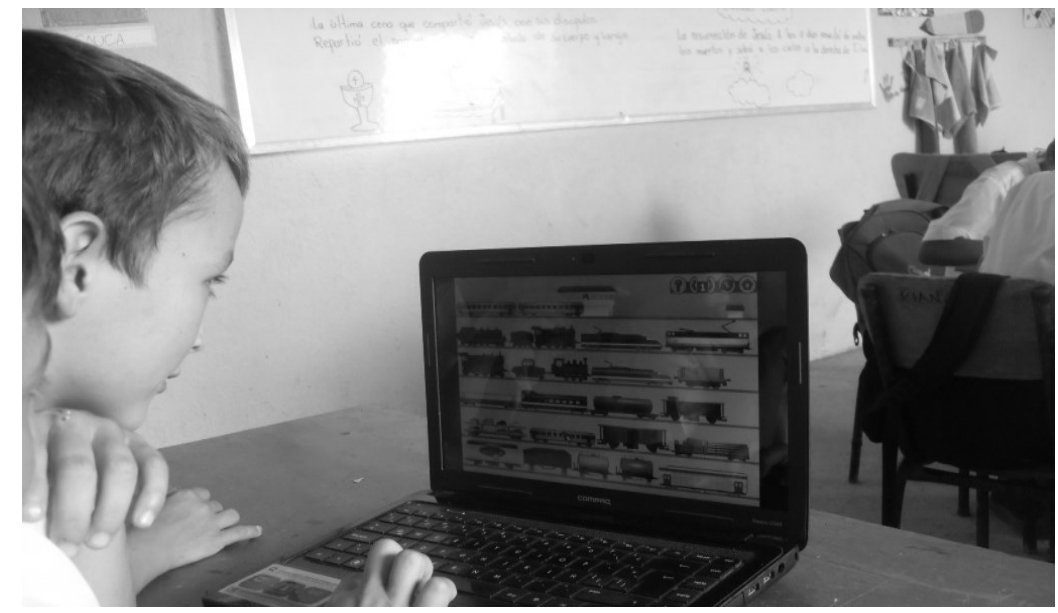

Figura 16. Estudiantes realizando actividades con REA

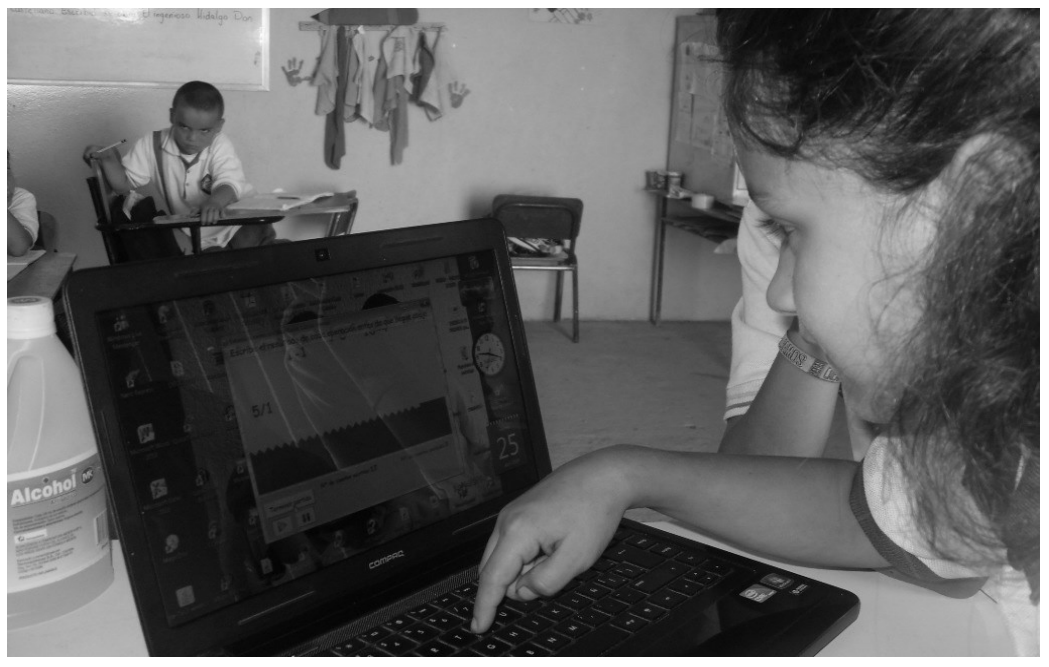

Figura 17. Estudiantes realizando actividades con REA 


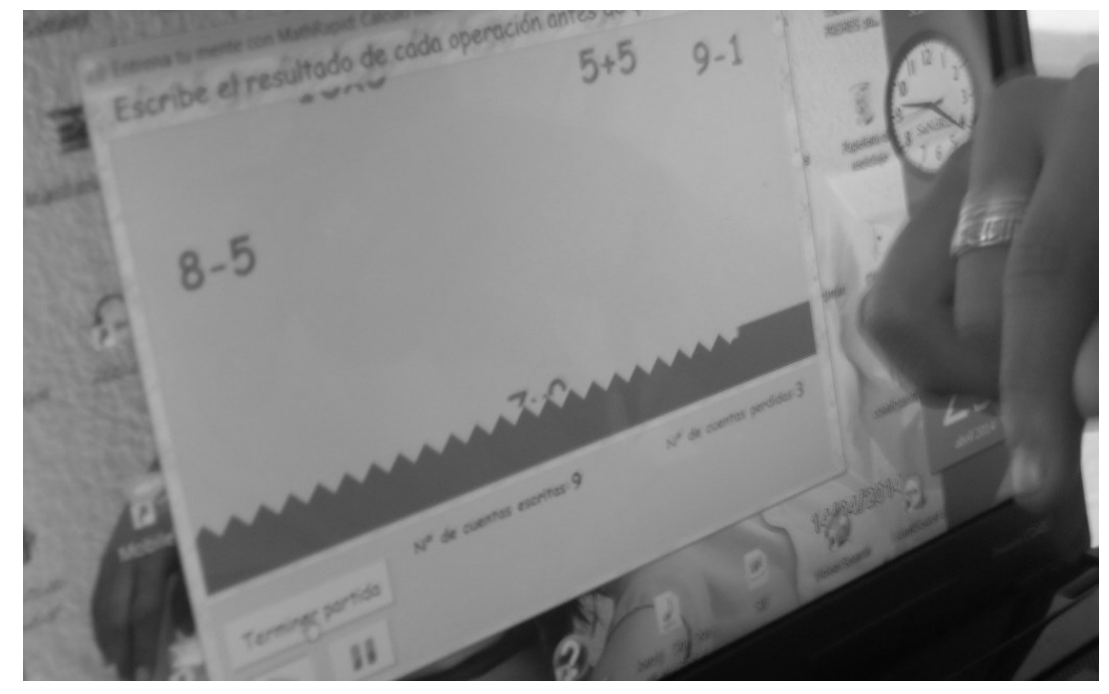

Figura 18. Actividad de operaciones matemáticas básicas 


\section{Currículum Vitae}

\section{Sandra Milena Lizarazo Gómez}

Correo electrónico personal: sandralizarazog@gmail.com

\section{Registro CVU 564480}

Originaria de Málaga, Santander, Colombia, Sandra Milena Lizarazo Gómez realizó estudios profesionales de Licenciatura en Educación Básica con énfasis en Ciencias Naturales y Educación Ambiental, en la Universidad Industrial de Santander. La investigación titulada "Desarrollo de la apropiación tecnológica con recursos educativos abiertos para el aprendizaje de educación básica primaria rural” es la que presenta en este documento para aspirar al grado de Maestría en Tecnología Educativa y Medios Innovadores para la Educación.

Su experiencia de trabajo ha girado, principalmente, alrededor del campo de la básica secundaria en áreas como Ciencias Naturales y Educación Ambiental y Artística y en básica primaria en todas las áreas del conocimiento, desde hace seis años.

Asimismo, ha participado en iniciativas de proyectos institucionales de escuela de padres.

Actualmente, Sandra Milena Lizarazo Gómez funge como docente de educación básica, en el nivel primaria en una escuela rural del municipio de Girón, Santander, en un aula multigrado. Sus expectativas giran en torno a contribuir en cerrar la brecha digital presente en algunos contextos rurales y aplicar tecnología educativa a los procesos de enseñanza aprendizaje en los mismos. 